\title{
Postsynaptic Density Assembly Is Fundamentally Different from Presynaptic Active Zone Assembly
}

\author{
Tal Bresler, ${ }^{1}$ Mika Shapira, ${ }^{1}$ Tobias Boeckers, ${ }^{2}$ Thomas Dresbach, ${ }^{3}$ Marie Futter, ${ }^{4}$ Craig C. Garner, ${ }^{5}$ Kobi Rosenblum, \\ Eckart D. Gundelfinger, ${ }^{3}$ and Noam E. Ziv ${ }^{1}$ \\ ${ }^{1}$ Rappaport Institute and the Department of Anatomy and Cell Biology, Technion Faculty of Medicine, Haifa 31096, Israel, ${ }^{2}$ Institute of Anatomy and Cell \\ Biology, University of Ulm, Ulm 89081, Germany, ${ }^{3}$ Department of Neurochemistry and Molecular Biology, Leibniz Institute for Neurobiology, Magdeburg \\ D-39118, Germany, ${ }^{4}$ Division of Physical Biochemistry, National Institute for Medical Research, London NW7 1AA, United Kingdom, ${ }^{5}$ Department of \\ Psychiatry and Behavioral Science, Nancy Pritzker Laboratory, Stanford University, Palo Alto, California 94304-5485, and ${ }^{6}$ Faculty of Science, Haifa \\ University, Haifa 31905, Israel
}

The cellular mechanisms involved in the formation of the glutamatergic postsynaptic density (PSD) are mainly unknown. Previous studies have indicated that PSD assembly may occur in situ by a gradual recruitment of postsynaptic molecules, whereas others have suggested that the PSD may be assembled from modular transport packets assembled elsewhere. Here we used cultured hippocampal neurons and live cell imaging to examine the process by which PSD molecules from different layers of the PSD are recruited to nascent postsynaptic sites. GFP-tagged NR1, the essential subunit of the NMDA receptor, and ProSAP1/Shank2 and ProSAP2/Shank3, scaffolding molecules thought to reside at deeper layers of the PSD, were recruited to new synaptic sites in gradual manner, with no obvious involvement of discernible discrete transport particles. The recruitment kinetics of these three PSD molecules were remarkably similar, which may indicate that PSD assembly rate is governed by a common upstream rate-limiting process. In contrast, the presynaptic active zone (AZ) molecule Bassoon was observed to be recruited to new presynaptic sites by means of a small number of mobile packets, in full agreement with previous studies. These findings indicate that the assembly processes of PSDs and AZs may be fundamentally different.

Key words: postsynaptic; presynaptic; synaptogenesis; ProSAP; NMDA; Bassoon

\section{Introduction}

A pronounced feature of the CNS glutamatergic synapse is its structural and molecular asymmetry. Structurally, the presynaptic compartment is characterized by neurotransmitter-filled synaptic vesicles (SVs) and the active zone (AZ), an electron-dense meshwork where SVs dock and fuse with plasma membrane. The postsynaptic compartment is characterized by the postsynaptic density (PSD), an electron-dense thickening juxtaposed against the presynaptic AZ. Whereas the AZ contains molecules that enable the controlled secretion of glutamate, the PSD contains large multimolecular complexes that respond to glutamate by altering membrane conductance and activating second messenger pathways. Although much has been learned on the molecular organization of the AZ and PSD (Garner et al., 2000; Kennedy, 2000; Scannevin and Huganir, 2000; Dresbach et al., 2001; Murthy and De Camilli, 2003) and on molecules involved in their differentiation (Garner et al., 2002; Scheiffele, 2003), relatively little is known about the cellular processes by which these structures are

Received Aug. 15, 2003; revised Nov. 17, 2003; accepted Dec. 23, 2003.

This work was supported by grants from the German Israel Foundation (686/2000) to N.E.Z. and E.D.G. and by the Deutsche Forschungsgemeinschaft (DR 373/3-1) to T.D., E.D.G., and N.E.Z. We are grateful to Larisa Goldfeld and Vladimir Lyakhov for their invaluable technical assistance.

Correspondence should be addressed to Dr. Noam E. Ziv, Department of Anatomy and Cell Biology, Technion Faculty of Medicine, P.0. Box 9649, Haifa 31096, Israel. E-mail: noamz@netvision.net.il.

DOI:10.1523/JNEUROSCI.3819-03.2004

Copyright $\odot 2004$ Society for Neuroscience $\quad$ 0270-6474/04/241507-14\$15.00/0 assembled (Ziv and Garner, 2001; Goda and Davis, 2003; McGee and Bredt, 2003).

Previous studies have shown that functional AZs can form within 30-60 min of initial axodendritic contact (for review, see Ziv and Garner, 2001). One type of mechanism that could account for the relatively rapid formation of AZs is one based on modular units of AZ material transported to nascent presynaptic sites as preformed precursors (Roos and Kelly, 2000). Indeed, multiple AZ molecules were found to be carried on $80 \mathrm{~nm}$ axonal dense-core vesicles named Piccolo-Bassoon transport vesicles (PTVs), and it has been suggested that new AZs might be formed by the fusion of PTVs with the presynaptic plasma membrane (Zhai et al., 2001; Shapira et al., 2003). Similarly, SV packets were shown to be transported and recruited to new presynaptic sites together with other presynaptic molecules, including voltagedependent calcium channels, synapsin, and amphiphysin (Ahmari et al., 2000).

The mode of PSD assembly is less clear. Previous studies indicated that the recruitment of SAP90/PSD-95 (a prominent PSD molecule) to new synaptic sites is protracted somewhat in comparison to AZ formation (Vardinon-Friedman et al., 2000; Okabe et al., 2001a). Furthermore, the recruitment of SAP90/PSD-95 (and PSD-Zip45/Homer 1c) to new synaptic sites was reported to occur in a gradual manner, not from readily discernible precursor particles (Bresler et al., 2001; Marrs et al., 2001; Okabe et al., 2001a,b). However, discrete and mobile SAP90/PSD-95 particles 
were observed in some studies, leading to suggestions that these might constitute modular PSD units (Marrs et al., 2001; Prange and Murphy, 2001). A more recent report showed that NMDA and AMPA receptors may be transported to nascent synapses as large discrete particles, and it was suggested that these could constitute modular glutamate receptor transport packets (Washbourne et al., 2002). In light of these conflicting findings, fundamental mechanistic questions concerning PSD assembly remain open: Is the PSD assembled from a small number of modular units? If not, how is it assembled? Where do postsynaptic molecules associate into the multi-molecular complexes found at PSDs? Are individual PSD molecules recruited separately and sequentially to nascent synaptic sites? Are they recruited collectively?

Here we examined how three PSD molecules, the NMDA receptor subunit NR1 and the scaffolding molecules ProSAP1 and ProSAP2, are recruited to nascent synaptic junctions. The recruitment of all three molecules was found to occur in a gradual manner, with very similar kinetics and with no obvious involvement of discernible modular transport packets. In contrast, the AZ molecule Bassoon was observed to be recruited from discrete and mobile transport particles, indicating that PSD and AZ assembly mechanisms may be fundamentally different.

\section{Materials and Methods}

Cell culture. Hippocampal cell cultures were prepared as described previously (Vardinon-Friedman et al., 2000). Briefly, hippocampal CA1CA3 regions were dissected from 1- to 2-d-old Sprague Dawley rats, dissociated by trypsin treatment, followed by trituration with a siliconized Pasteur pipette, and then plated onto coverslips coated with poly-D-lysine (Sigma, St. Louis, MO) inside 8-mm-diameter glass cylinder (Bellco Glass, Vineland, NJ) microwells. Culture medium consisted of MEM (Invitrogen, San Diego, CA), 0.6\% glucose, $0.1 \mathrm{gm} / 1$ bovine transferrin (Calbiochem, La Jolla, CA), $0.25 \mathrm{gm} / \mathrm{l}$ insulin (Sigma), 0.3 gm/l glutamine, 5-10\% fetal calf serum (Sigma), 2\% B-27 supplement (Invitrogen), and $8 \mu \mathrm{M}$ cytosine $b$-D-arabinofuranoside (Sigma). Cultures were maintained at $37^{\circ} \mathrm{C}$ in a $95 \%$ air $/ 5 \% \mathrm{CO}_{2}$ humidified incubator, and culture medium was replaced every $7 \mathrm{~d}$.

DNA constructs. NR1:GFP (green fluorescent protein) was constructed by amplification of full-length NR1-1a (a gift from Dr. Ralf Schoepfer, University College London, UK), using PCR and the following primers: 5'-AATAAGCTTCTCATGAGCACCATGCACCTG- $3^{\prime}$ and $5^{\prime}$-GTGCGGATCCTGCGCTCTCCCTATGACGGGAACA-3'. The PCR product was digested with HindIII and BamHI and ligated into pEGFP-N3 (Clontech, Cambridge, UK), resulting in NR1 tagged with GFP at its C terminus. For ProSAP/Shank GFP-expression constructs full-length ProSAP1A (accession number AJ249562) and ProSAP2 (Shank3; accession number AJ133120) cDNAs were cloned into the pEGFPC1 or pEGFPC2 (Clontech) expression vectors by using endogenous restriction sites. The GFP:Bsn95-3938 construct used here was described previously (Dresbach et al., 2003).

Expression of enhanced GFP-tagged proteins in hippocampal neurons. Transfection of hippocampal neurons was based on the calcium phosphate transfection method described by Kohrmann and coworkers (1999). Briefly, cells raised in culture for 5-7 d were washed with fresh, serum-free medium (MEM $+5 \mathrm{gm} / \mathrm{l}$ glucose), after saving the original medium, and left in the incubator for $45 \mathrm{~min}$. Then $6 \mu \mathrm{l}$ of a calciumphosphate precipitate-DNA mixture (see below) was added to each glass cylinder, and the cells were returned to an incubator with an atmospheric environment of $2.5 \% \mathrm{CO}_{2} / 97.5 \%$ air for $90-105 \mathrm{~min}$. Cells then were washed twice with HEPES-buffered medium (HBS) and twice with serum-free medium, after which the original growth medium was returned to the glass cylinders. Precipitate was prepared by adding $5 \mu \mathrm{g}$ of DNA to $60 \mu \mathrm{l}$ of $2 \mathrm{M} \mathrm{CaCl}_{2}$ and then adding $60 \mu \mathrm{l}$ of $2 \times N, N$-bis $(2-$ hydroxyethyl)-2-aminoethanesulfonic acid (BES) solution, $\mathrm{pH}$ 6.95, while vigorously mixing the test tube (for HBS and BES solution formu- lations, see Kohrmann et al., 1999). Precipitate mixture was adding immediately to cloning cylinders. Transfection was evaluated after $24 \mathrm{hr}$ by fluorescence microscopy. Expression of exogenous DNA typically was detected in 3-10 neurons per cloning cylinder.

Microscopy. Scanning fluorescence and differential interference contrast images were acquired via a custom-designed confocal laser scanning microscope (CLSM) based on a Zeiss Axiovert 100 (Oberkochen, Germany), using a $40 \times 1.3$ numerical aperture Fluar objective. The system is controlled by software written by one of us (N.E.Z.) and includes provisions for automated, multi-site time-lapse microscopy (VardinonFriedman et al., 2000; Bresler et al., 2001). Enhanced GFP (EGFP) and FM4-64 were excited by using the $488 \mathrm{~nm}$ line of an argon laser. Fluorescence emissions were read with $500-545 \mathrm{~nm}$ bandpass and $>630 \mathrm{~nm}$ long-pass filters, respectively (Chroma Technology, Brattleboro, VT). Time-lapse recordings usually were performed by averaging three frames collected at each of three to seven focal planes spaced $0.7 \mu \mathrm{m}$ apart. All data were collected at $640 \times 480$ resolution, at $12 \mathrm{bits} /$ pixel, with the confocal aperture partially open. To increase experimental throughput, we collected data sequentially from up to 10 (but usually 2-5) predefined sites, using the CLSM robotic XYZ stage to cycle automatically through these sites at predetermined time intervals. Focal drift during the experiment was corrected automatically by using the CLSM "autofocus" feature.

In most experiments the preparations were imaged within their cloning cylinders in the presence of their growth medium (no perfusion). The coverslips were mounted in a modified heated chamber (Warner Instruments, Hamden, CT) and placed in a custom-designed enclosure flooded with a sterile mixture of $5 \% \mathrm{CO}_{2} / 95 \%$ air. The chamber and objective were heated to $37-38^{\circ} \mathrm{C}$, using resistors and thermal foil, and were controlled separately. This setup resulted in stable intrachamber temperatures of $37^{\circ} \mathrm{C}$.

Functional labeling of presynaptic boutons with FM4-64. Functional presynaptic boutons were visualized by loading them with FM4-64 [ $N$-(3-triethylammoniumpropyl)-4-( $p$-dibutylaminostyryl)pyridinium, dibromide, Molecular Probes, Eugene, OR]. For these experiments the cloning cylinder was removed, and the cells were perfused with Tyrode's saline solution [containing (in $\mathrm{mM}$ ): $119 \mathrm{NaCl}, 2.5 \mathrm{KCl}, 2 \mathrm{CaCl}_{2}, 2 \mathrm{MgCl}_{2}, 25$ HEPES, and 30 glucose, buffered to $\mathrm{pH} 7.4$ ] to which the ionotropic glutamate receptor antagonist 6,7-dinitroquinoxaline-2,3-dione (DNQX; Research Biochemicals, Natick, MA) was added from $2000 \times$ stocks in dimethyl sulfoxide (DMSO) to a final concentration of $10 \mu \mathrm{M}$. Cells were exposed to FM4-64 by flooding the perfusion chamber with Tyrode's containing $15 \mu \mathrm{M}$ FM4-64 and $10 \mu \mathrm{M}$ DNQX. Then the neurons were stimulated to fire action potentials by passing $1 \mathrm{msec}$ current pulses through platinum electrodes placed on both sides of the chamber. The cells were stimulated for $30 \mathrm{sec}$ at $10 \mathrm{~Hz}$, left in the dye for an additional $30 \mathrm{sec}$, washed for $1 \mathrm{~min}$ with 1 mM ADVASEP 7 ( $\beta$-cyclodextrin sulfbutyl ether; CyDex, Overland Park, $\mathrm{KS}$ ) in Tyrode's solution containing $10 \mu \mathrm{M}$ DNQX, and rinsed with Tyrode's for 2-3 min. Dye unloading was performed by stimulating the neurons for $120 \mathrm{sec}$ at $10 \mathrm{~Hz}$.

Retrospective immunohistochemistry. Neurons were fixed by flooding the perfusion chamber with a fixative solution consisting of $4 \%$ formaldehyde and $120 \mathrm{~mm}$ sucrose in PBS or cold $\left(-18^{\circ} \mathrm{C}\right)$ methanol (for NR1 labeling) for $20 \mathrm{~min}$. The cells were permeabilized for $10 \mathrm{~min}$ in fixative solution to which $0.25 \%$ Triton X-100 (Sigma) was added. The cells were washed three times in PBS, incubated in $10 \%$ bovine serum albumin (BSA) for $1 \mathrm{hr}$ at $37^{\circ} \mathrm{C}$, and incubated overnight at $4^{\circ} \mathrm{C}$ or room temperature with primary antibodies in PBS and 1\% BSA. Then the cells were rinsed three times for $10 \mathrm{~min}$ with PBS and incubated for $1 \mathrm{hr}$ at room temperature with secondary antibodies in PBS and 1\% BSA. The cells were rinsed again with PBS, mounted, and imaged immediately.

Primary antibodies used in this study included monoclonal mouse anti NR1 (clone 54.1; Becton Dickinson Biosciences Pharmingen, San Diego, CA), rabbit and guinea pig anti-ProSAP1 and ProSAP2 (Boeckers et al., 1999a; Bockmann et al., 2002), monoclonal mouse anti-SAP90/ PSD-95 [clone 7E3-1B8 (Affinity BioReagents, Golden, CO) and clone K28/43 (Upstate Biotechnology, Lake Placid, NY)], rabbit anti-synapsin I, rabbit anti-GluR1 (Chemicon, Temecula, CA), and monoclonal antimicrotubule-associated protein (MAP) 2 (clone HM-2; Sigma). Second- 
ary antibodies included tetramethylrhodamine goat anti-rabbit IgG, AlexaFluor 633 IgG goat anti-mouse IgG and IgG2a (Molecular Probes), Cy5 AffiniPure donkey anti-guinea pig IgG, and Cy5 AffiniPure donkey anti-mouse IgG (Jackson ImmunoResearch Laboratories, West Grove, PA).

The location of the same sites for which data were collected during experiments was performed as previously described (Bresler et al., 2001). Images of immunolabeled cells were collected by averaging four frames at six sections spaced $0.5 \mu \mathrm{m}$ apart, with the confocal aperture nearly fully closed. Tetramethylrhodamine fluorescence was recorded at $532 \mathrm{~nm}$ excitation (frequency-doubled NdYag laser line)/>565 nm emission and AlexaFluor 633/Cy-5 fluorescence was recorded at $633 \mathrm{~nm}$ excitation (helium-neon 633 line)/>650 emission.

Image analysis. All data analysis was performed with software ("OpenView”) written for this purpose by one of us (N.E.Z.). Analysis was performed on maximal intensity projections of $z$-section stacks. Digital movies of time-lapse sequences were prepared for each site and thereafter used for evaluating the dynamics of fluorescent puncta and for detecting new clusters of synaptic molecules.

Quantitative analyses of exogenous molecule expression levels were performed as follows: $8 \times 8$ pixel $(\sim 1.2 \times 1.2 \mu \mathrm{m})$ analysis boxes were centered over fluorescent puncta in maximal intensity projection images of fixed and immunolabeled neurons that expressed the fluorescently tagged molecules. In each dish the immunolabeled puncta were divided into two groups according to the presence or absence of GFP (presumably reflecting puncta belonging to neurons expressing GFP-tagged synaptic molecules and naive neurons, respectively), and the average fluorescence intensities of immunolabeled puncta in each group were calculated and compared (see also Bresler et al., 2001).

Changes in the fluorescence intensity of new GFP-tagged postsynaptic protein clusters were measured in original image sets by centering an $8 \times$ 8 pixel box on the new cluster and measuring the summed intensity in this box. These measurements then were performed in all consecutive frames. The background fluorescence was measured separately for each new cluster by measuring the average fluorescence in the image collected just before the first appearance of the new cluster at the location in which it appeared in the subsequent frame. All intensity measurements of all new clusters were normalized by subtracting the background intensity from all subsequent measurements and dividing all resulting values by the (background-subtracted) peak intensity value collected for that cluster during the time-lapse session. Then the normalized values for all new clusters were averaged for each time point, in which time 0 was considered to be the time of the frame collected just before the first appearance of the new cluster. Only clusters followed for at least 30 min were included in this analysis.

Fluorescence intensity measurements of preexisting clusters and normalization of these data were performed in a similar manner except that in this case no background subtraction was performed.

Quantitative assessment of association of GFP-tagged protein clusters with FM4-64-labeled puncta or immunolabeled clusters of other synaptic molecules was performed as described previously (Shapira et al., 2003)

Images for figures were processed by low-pass filtering $(3 \times 3$ kernel $)$ and linear contrast enhancement. Figures were prepared with commercial software [Adobe Photoshop (Mountain View, CA) and Microsoft Excel and PowerPoint (Redmond, WA)].

\section{Results}

Previously, we have studied the recruitment of the PSD molecule SAP90/PSD-95 to new postsynaptic sites (Bresler et al., 2001), using a GFP-tagged variant of this molecule expressed in cultured hippocampal neurons. SAP90/PSD-95 is part of a large multimolecular complex that spans the PSD from the postsynaptic membrane to its intracellular aspect (Garner et al., 2000; Kennedy, 2000). To gain new insights as to how and where these complexes are formed, we examined the recruitment of additional members of this postsynaptic complex and compared their recruitment dynamics with those of SAP90/PSD-95. Specifically, we examined the recruitment dynamics of (1) NMDA-type glu- tamate receptors, integral membrane proteins that are thought to bind directly to SAP90/PSD-95 (Kornau et al., 1995; Niethammer et al., 1996), and (2) ProSAP1/2 (Shank 2/3), members of the Shank/ProSAP scaffolding molecule family (Sheng and Kim, 2000; Boeckers et al., 2002) that were shown to reside relatively far from the postsynaptic plasma membrane (Valtschanoff and Weinberg, 2001) and are thought to be linked to SAP90/PSD-95 via the PSD molecule GKAP/SAPAP (Boeckers et al., 1999b; Naisbitt et al., 1999). We reasoned that, by examining the recruitment dynamics of molecules at three different "layers" of the PSD, a more complete and faithful view of PSD assembly would be obtained.

\section{Recruitment of NMDA receptors to new synapses}

Functional NMDA receptors are formed from a mandatory NR1 subunit and one or more NR2 subunits, which in the hippocampus are most commonly the NR2A and NR2B subtypes (Sheng et al., 1994). NMDA receptors are thought to be maintained at the PSD by the association of their NR2A cytoplasmic carboxyl tails with PDZ domains of scaffolding molecules such as SAP90/PSD95. NR1-1a, the most common NR1 subunit splice variant expressed in the hippocampus, lacks a PDZ binding motif (Nakanishi et al., 1992; Laurie and Seeburg, 1994) and thus is thought to be targeted to synaptic sites by means of its association with NR2 subunits (for review, see Dingledine et al., 1999; Wenthold et al., 2003).

To study the dynamics of NMDA receptor recruitment to nascent postsynaptic sites, we expressed a GFP-tagged variant of the NR1-1a splice variant (NR1:GFP) in hippocampal neurons obtained from postnatal rats and grown in primary culture. In most cases, neurons expressing this construct displayed a punctate and dendritic expression pattern suggestive of a synaptic localization of this fusion protein (Fig. 1). Occasionally, however, neurons displayed diffuse fluorescence throughout their entire volume (data not shown) and were not analyzed further.

The fluorescence levels of cells expressing NR1:GFP were quite low in comparison to other GFP-tagged molecules we have examined in the past, suggesting that the NR1 overexpression levels in these neurons were very modest. This was confirmed by fixing the neurons, labeling them with an antibody against NR1 (Fig. $1 B, C$ ), and comparing the fluorescence levels of NR1 clusters with those of naive neurons in the same dish (NR1:GFPexpressing neurons: $413 \pm 99$ fluorescence units, 10 cells, 380 puncta; naive neurons: $421 \pm 117$ fluorescence units, six fields of view, 454 puncta).

The synaptic identity of the fluorescent puncta was verified by several means. First, NR1:GFP-expressing neurons were fixed and stained with antibodies against NR2A/B (Fig. 2 B), the AMPA receptor subunit 1 (GluR1; data not shown), and synapsin I (Fig. 2C). Most although not all NR1:GFP puncta colocalized with puncta of the immunolabeled synaptic molecules (NR2A/B, $72 \%$; GluR1, 50\%; synapsin I, 81\%). Second, functional presynaptic boutons in the field were labeled with the fluorescent dye FM4-64 (Cochilla et al., 1999; Vardinon-Friedman et al., 2000), and the fraction of NR1:GFP puncta associated with FM4-64labeled presynaptic boutons was determined (Fig. 2A). Of NR1: GFP puncta, $80 \%$ was observed to colocalize with a functional presynaptic bouton. In addition, the dendritic localization of NR1:GFP was verified by confirming that the distribution of NR1:GFP puncta was limited to neurites positive for the dendrite-specific molecule MAP2 (data not shown).

The recruitment dynamics of NR1:GFP to new synaptic junctions were examined by performing automated multi-site time- 

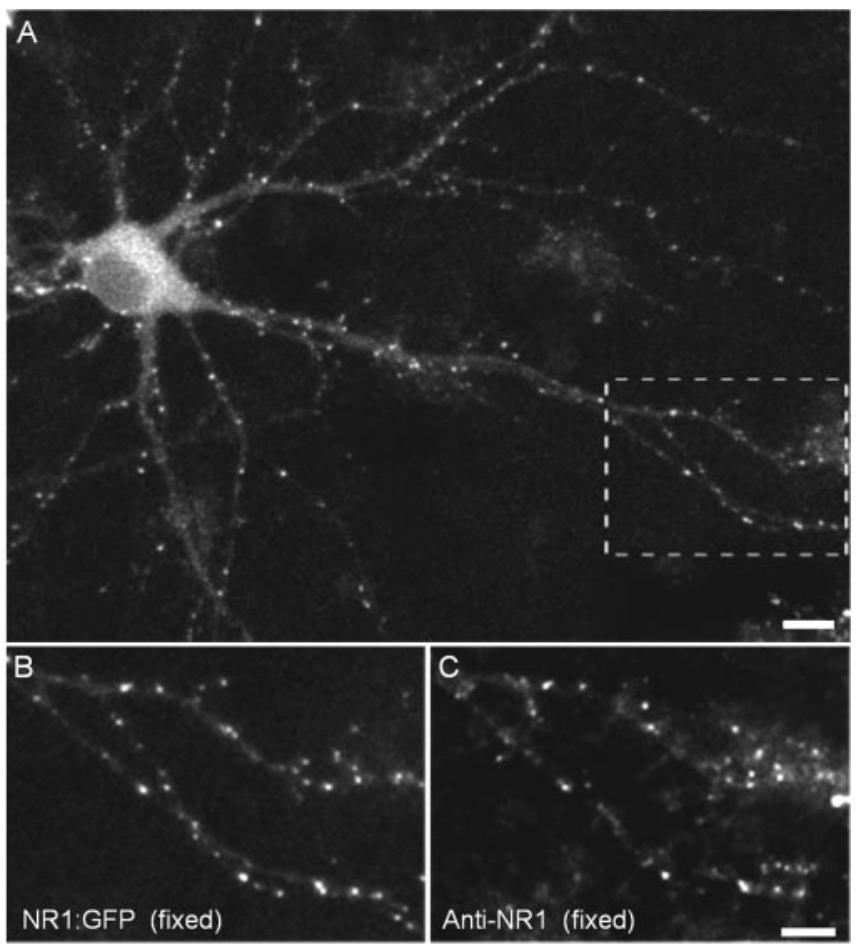

Figure 1. Expression pattern of NR1:GFP in cultured hippocampal neurons. A, Hippocampal neuron in primary culture expressing NR1:GFP ( $9 \mathrm{~d}$ in vitro). $B$, Higher magnification of the region enclosed in a rectangle in $A$ after fixation. C, Same region as in $B$ after immunolabeling against NR1. The expression pattern of NR1:GFP is punctate and suggestive of synaptic localization. Scale bars: $A, 10 \mu \mathrm{m} ; C, 5 \mu \mathrm{m}$.

lapse confocal microscopy recordings of neurons expressing NR1:GFP. All experiments were performed on preparations grown in culture for 7-13 d, the period of peak synapse formation in these preparations (Basarsky et al., 1994; Renger et al., 2001) and a period in which many synaptic proteins already are expressed (Rao et al., 1998). Coverslips onto which neurons were plated were mounted on the microscope stage in an enclosure that provided a sterile atmospheric environment of 5\% $\mathrm{CO}_{2} / 95 \%$ air. The neurons were maintained at $37^{\circ} \mathrm{C}$ by heating the chamber and the oil immersion microscope objective to this temperature. Time-lapse recordings were performed by collecting stacks of images at $10 \mathrm{~min}$ intervals for up to $2 \mathrm{hr}$. At the end of the experiment functional presynaptic boutons in the field were labeled via FM4-64 and field stimulation ( $30 \mathrm{sec}$ at $10 \mathrm{~Hz}$ ). After we obtained images of the labeled presynaptic boutons (in addition to those of NR1:GFP), a second train of action potentials was delivered to unload the dye trapped within synaptic vesicles to confirm the presynaptic identity of the fluorescent FM4-64 puncta, and a final set of images was collected. Then the neurons were fixed and processed for immunofluorescence.

After the experiments the time-lapse sequences were scrutinized for the appearance of new NR1:GFP clusters. In some cases one to two new clusters were observed to form in a field of view, whereas in others no new NR1:GFP clusters were observed during the entire time-lapse session. These rates are in agreement with the rates of new synapse formation in these preparations (Vardinon-Friedman et al., 2000) and the fact that only a small fraction of neurons expressed NR1:GFP. Ultimately, in 18 experiments (42 fields of view) we managed to record the appearance of 20 new synaptic clusters of NR1:GFP. As demonstrated in Figure $3 A$, new synaptic NR1 clusters appeared to form gradually
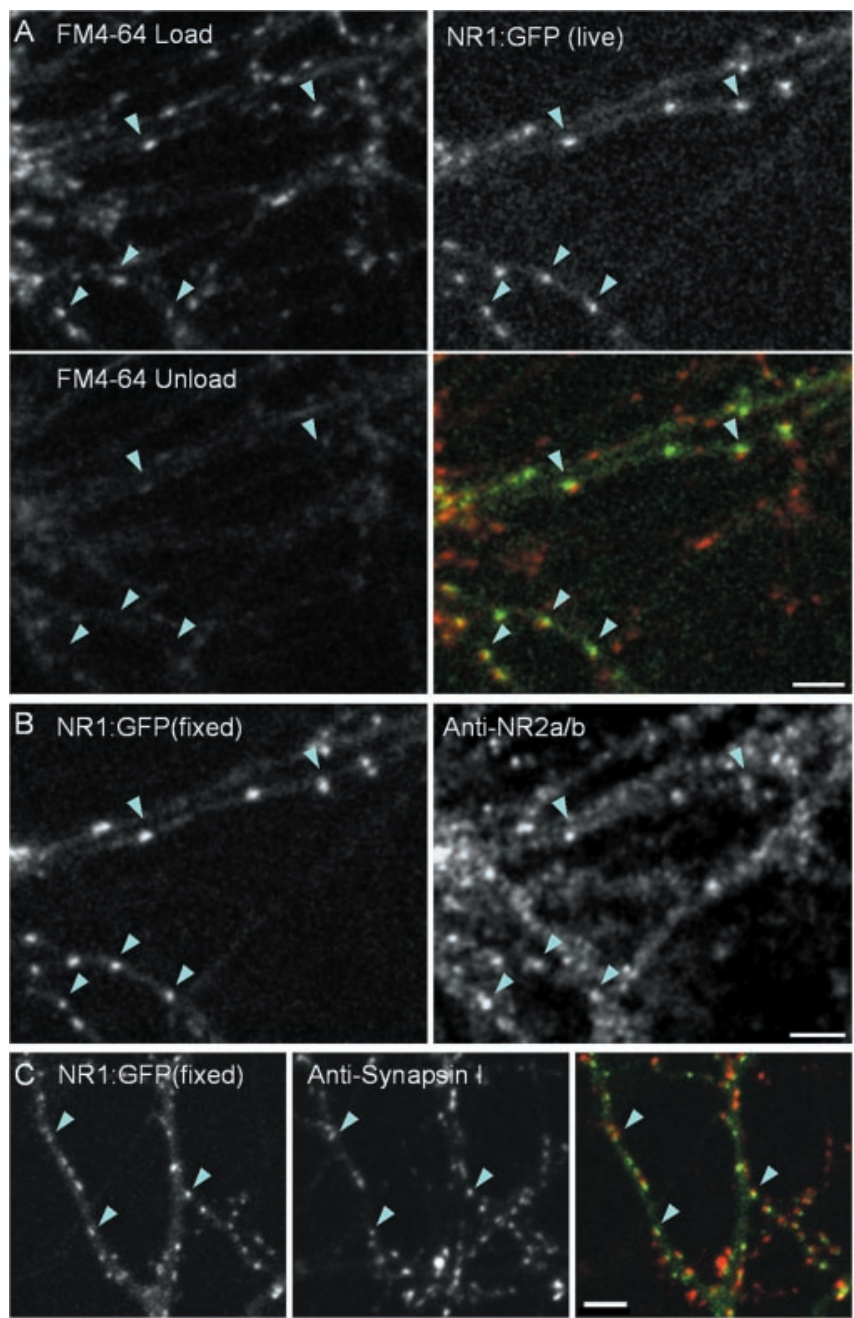

Figure 2. NR1:GFP is targeted correctly to postsynaptic sites. A, Presynaptic boutons were labeled by stimulating neurons to fire action potentials via field stimulation ( $30 \mathrm{sec}$ at $10 \mathrm{~Hz}$ ) in the presence of FM4-64 (top left). NR1:GFP (green puncta) were observed to colocalize with FM4-64 puncta (red puncta, right panels) for which the presynaptic identity was confirmed further by unloading the dye with a second train of stimuli ( $120 \mathrm{sec}$ at $10 \mathrm{~Hz}$ ). $B$, The same NR1:GFP clusters were fixed and immunolabeled with an antibody against the NR2A and NR2B subunits of NMDA receptors. Most NR1:GFP clusters colocalized with clusters of NR2A/B. C, Fixed NR1:GFP clusters (green puncta) were immunolabeled against the presynaptic molecule synapsin I (red puncta). Most NR1:GFP clusters were juxtaposed against synapsin I puncta. Arrowheads point to identical locations in all panels of $A-C$. Scale bars, $5 \mu \mathrm{m}$.

over $\sim 30-40$ min from the moment they first were observed, which is shown in a more quantitative manner in Figure $4 \mathrm{~A}$. In none of these cases did we observe the involvement of readily detectable large and mobile transport particles. As shown in Figure $3 B$, the synaptic identity of these new puncta was confirmed by the presence of FM4-64-labeled presynaptic boutons juxtaposed against the new NR1:GFP clusters.

Although the vast majority of preexisting NR1:GFP puncta was relatively static, we observed a small number $(<1 \%)$ of fluorescent puncta that moved very slowly along dendrites at rates of $\sim 0.01 \mu \mathrm{m} / \mathrm{sec}$ (maximal velocities of $0.03 \mu \mathrm{m} / \mathrm{sec}$ ), covering distances of a few micrometers $(<10)$ over $1-2 \mathrm{hr}$. These mobility characteristics were quite different from those expected of typical transport particles but were very similar to those described previously for mobile clusters of GFP-tagged SAP90/PSD-95 (Bresler et al., 2001; Marrs et al., 2001; Prange and Murphy, 2001). We have observed previously that, in dissociated neuronal 

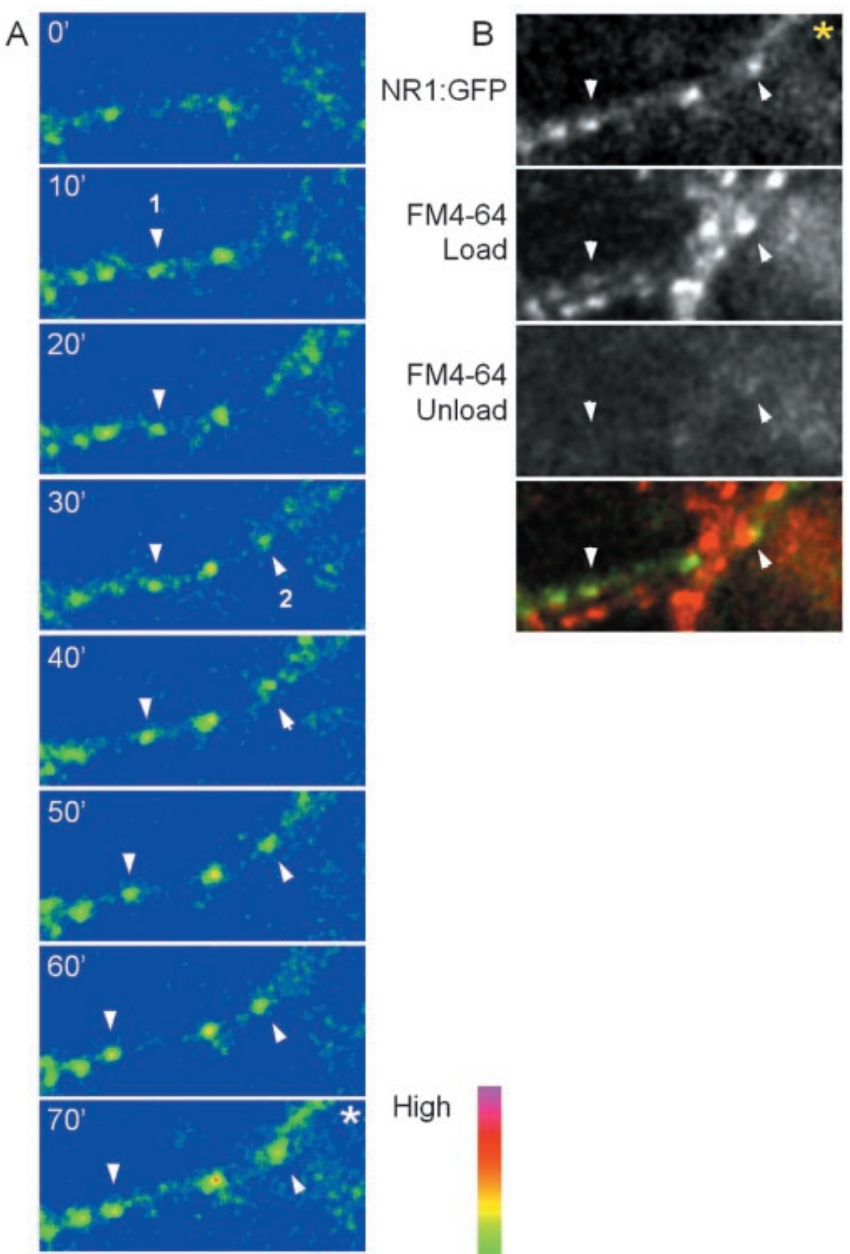

High

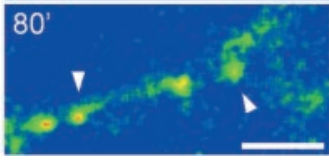

Low

Figure 3. Gradual formation of new NR1:GFP clusters. A, The formation of two new NR1:GFP clusters $(1,2$, arrowheads) is shown in this time-lapse sequence of a dendritic segment of a neuron expressing NR1:GFP (13 din vitro). Note the gradual increase in the fluorescence intensity of these new clusters (coded according to the pseudocolor look-up table on the right). A quantitative analysis of the fluorescence intensity for these new clusters is shown in Figure $4 \mathrm{~A}$. $B$, FM4-64 labeling performed at the end of the experiment revealed that the new NR1:GFP clusters (green puncta) were juxtaposed against functional presynaptic boutons (red puncta), suggesting that new synapses had formed at these sites. All times are given in minutes. Asterisks mark identical images in $A$ and $B$. Scale bar, $5 \mu \mathrm{m}$.

cultures, entire synapses often display movements of this nature (Bresler et al., 2001), probably because of forces exerted by elongating axons and dendrites, protrusive structures such as filopodia, and underlying glia. We thus labeled functional presynaptic boutons in the preparations with FM4-64 and concomitantly followed the NR1:GFP and FM4-64 puncta by time-lapse microscopy. Here, too, we observed that most apparently mobile NR1: GFP puncta moved in unison with cognate FM4-64 puncta, suggesting that these were, in fact, synapses displaying some degree of positional instability (data not shown). Conversely, we consistently observed a fraction of NR1:GFP puncta that did not colocalize with other synaptic markers such as synapsin I, SAP90/ PSD-95, or FM4-64-labeled presynaptic boutons (Fig. 2) (see also Rao and Craig, 1997; Rao et al., 1998). Time-lapse imaging of these NR1:GFP clusters suggested, however, that they were no
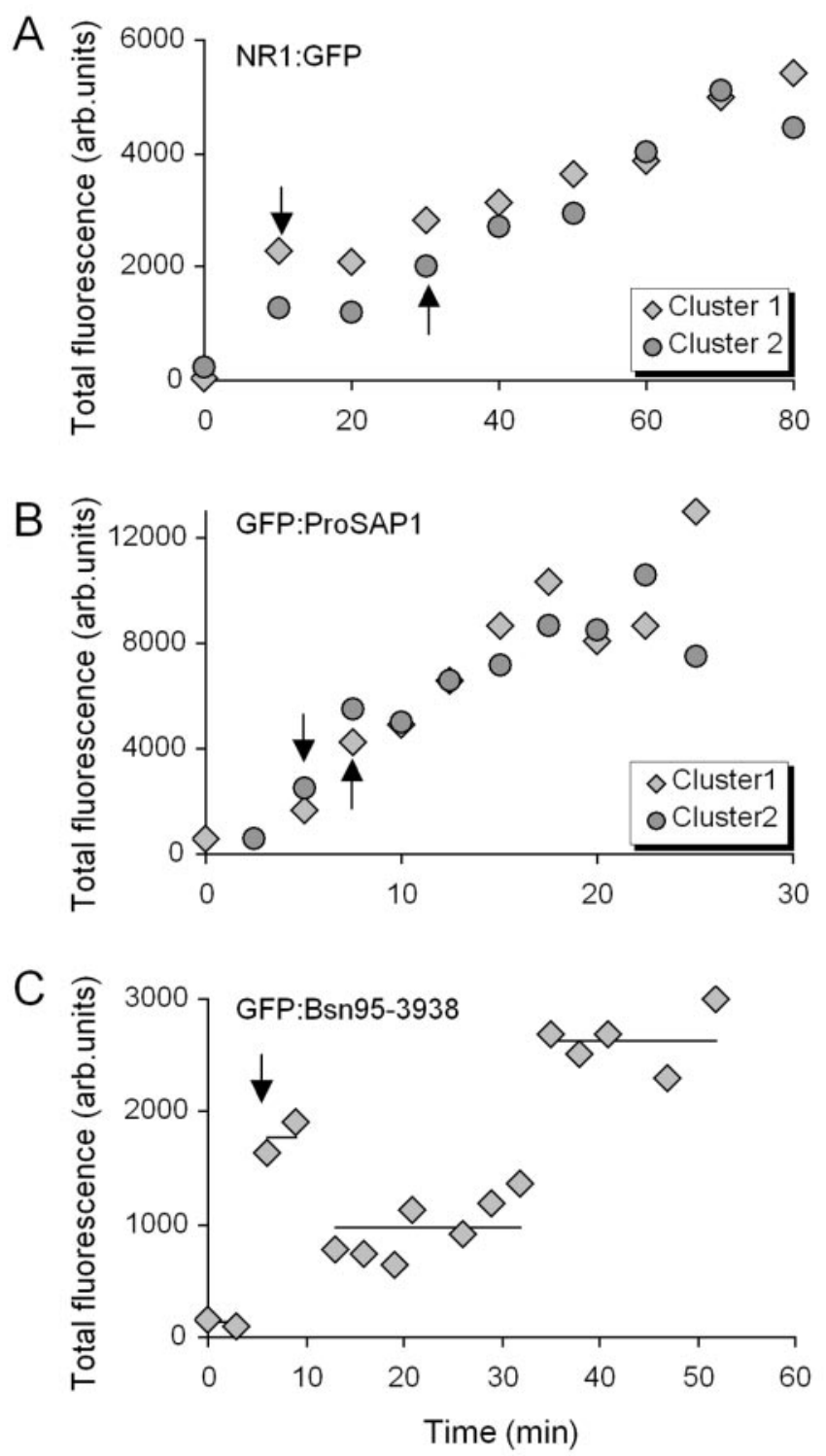

Figure 4. Accumulation of NR1:GFP and GFP:ProSAP1 at new synaptic sites is qualitatively different from GFP:Bsn95-3938 accumulation. Shown is quantification of the fluorescence intensities of the two new NR1:GFP clusters in Figure $3(A)$, the two new GFP:ProSAP1 clusters in Figure $6(B)$, and the new GFP:Bsn95-3938 cluster in Figure 11 (C). Whereas NR1:GFP and GFP:ProSAP1 show gradual increases in fluorescence intensity over time, GFP:Bsn95-3938 shows stepwise fluorescence intensity changes. Arrows mark the time points at which punctate fluorescence was first observed at these sites. Cluster numbers in $A$ and $B$ match those of Figures 3 and 6, respectively. Horizontal lines in C are averages of fluorescence intensities in each step.

more mobile than NR1:GFP puncta associated with additional synaptic markers, making it unlikely that these represented a population of bona fide transport particles.

These experiments thus indicate that NMDA receptors can be recruited to nascent postsynaptic sites in a gradual manner without a requirement for large and discrete transport particles.

\section{Recruitment of ProSAP1 and ProSAP2 to new synapses}

ProSAPs/Shanks are postsynaptic multidomain proteins that interact directly and indirectly with a large number of synaptic proteins (Sheng and Kim, 2000; Boeckers et al., 2002). In particular, ProSAPs/Shanks interact with NMDA-type glutamate receptors (via GKAP/SAPAP and SAP90/PSD-95; Boeckers et al., 1999b; Naisbitt et al., 1999), with metabotrophic glutamate re- 


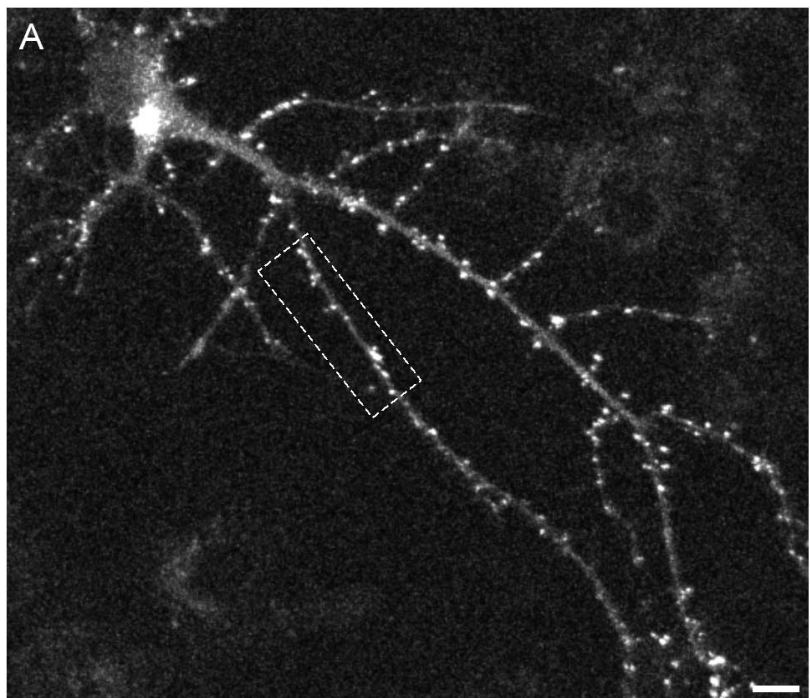

B

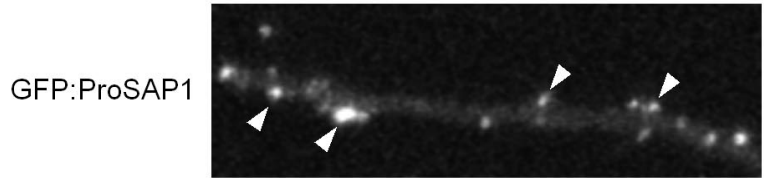

SAP90/PSD-95

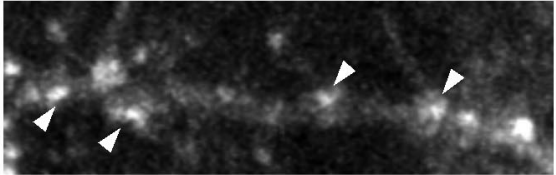

Synapsin

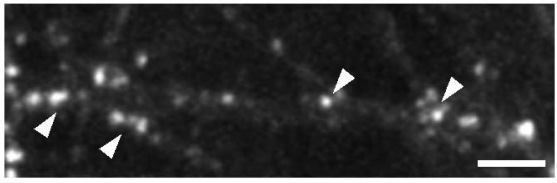

Figure 5. GFP:ProSAP1 is targeted correctly to synaptic sites. A, Hippocampal neuron in primary culture expressing GFP:ProSAP1 ( $9 \mathrm{~d}$ in vitro). $B$, Higher magnification of the region enclosed in the rectangle in $A$ after fixation and immunolabeling against the postsynaptic molecule SAP90/PSD-95 and the presynaptic molecule synapsin I. Most ProSAP1 puncta colocalized with these two synaptic molecules (arrowheads). Scale bars: $A, 10 \mu \mathrm{m} ; B, 5 \mu \mathrm{m}$.

ceptors (via Homer/VESL; Tu et al., 1999), and possibly with AMPA receptors via glutamate receptor interacting protein (GRIP) (Sheng and Kim, 2000). In addition, ProSAPs (also known as cortactin binding protein, CortBP) interact with the actin-based cytoskeleton via cortactin (Du et al., 1998) and $\alpha$-fodrin (Böckers et al., 2001). Thus ProSAPs/Shanks have been considered to constitute "master scaffold" PSD molecules that anchor different types of glutamate receptors to cytoskeletal elements (for review, see Sheng and Kim, 2000; Boeckers et al., 2002).

The ProSAP/Shank family includes three members that share a high-sequence similarity but that differ somewhat in their spatial and temporal expression profiles. Here we focused on the recruitment of ProSAP1 (Shank2/CortBP1/Spank3) and ProSAP2 (Shank3) to nascent synapses. To that end we expressed GFP-tagged variants of these molecules in cultured hippocampal neurons as described above for NR1. Both GFP:ProSAP1 (Fig. 5A) and GFP:ProSAP2 (data not shown) display a punctate expression pattern that is suggestive of a synaptic localization of these fusion proteins. Indeed, most GFP:ProSAP1 and GFP:ProSAP2 puncta colocalize with various synaptic markers such as SAP90/PSD-95 and synapsin I (Fig. 5B). However, an agedependent fraction appeared to be nonsynaptic ( $\sim 18 \%$ at $5 \mathrm{~d}$ in vitro and $\sim 10 \%$ at $9 \mathrm{~d}$ in vitro).
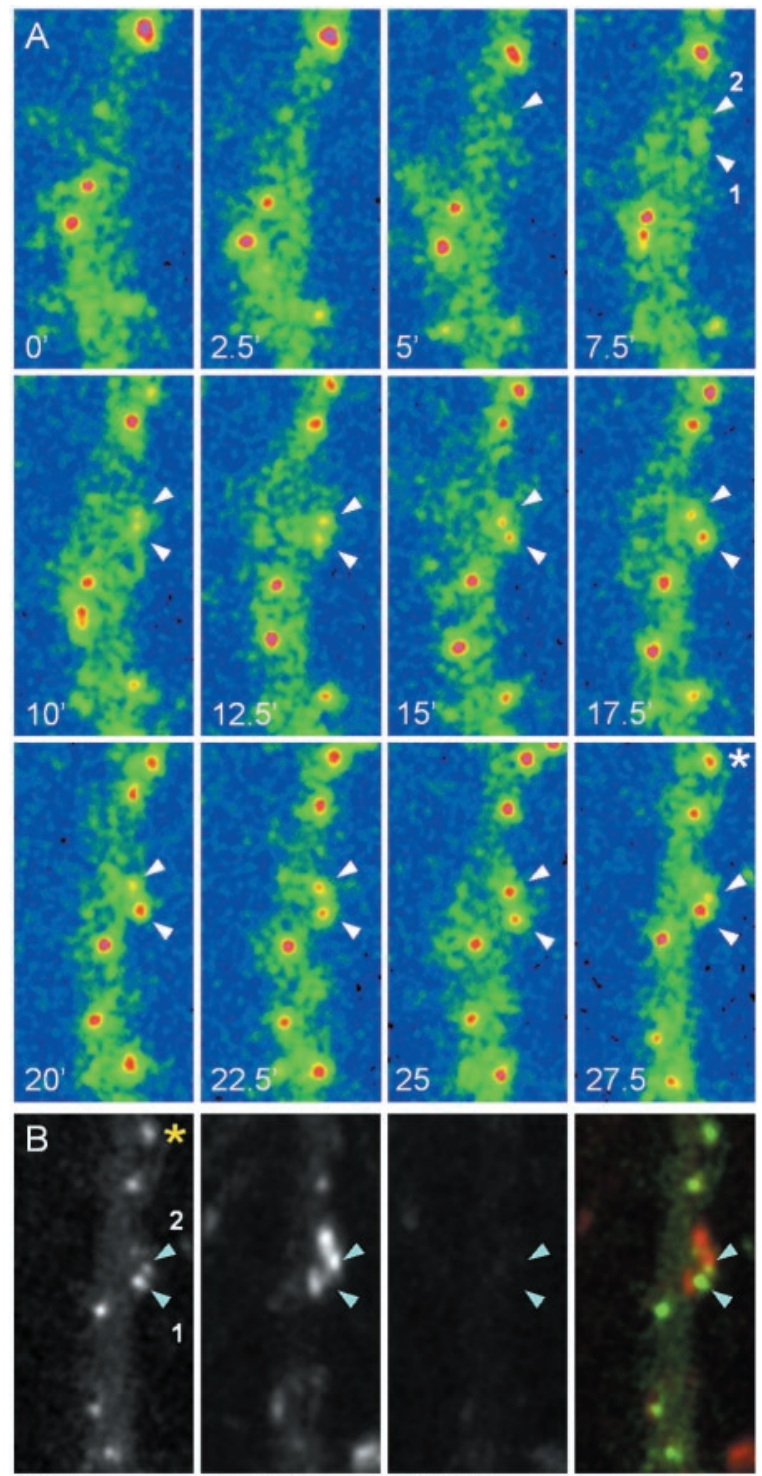

GFP:

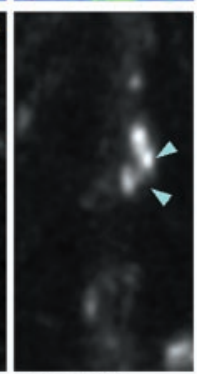

ProSAP1

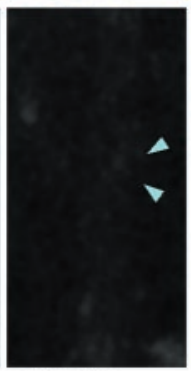

FM4-64

Unload

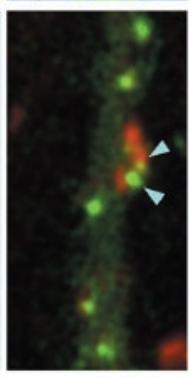

Figure 6. Gradual formation of new GFP:ProSAP1 clusters. $A$, The formation of two new GFP:ProSAP1 clusters (1, 2, arrowheads) is shown in this time-lapse sequence of a dendritic segment of a neuron expressing GFP:ProSAP1 ( $8 \mathrm{~d}$ in vitro). Note the gradual increase in the fluorescence intensity of these new clusters (coded in pseudocolor as in Fig. 3). A quantitative analysis of the fluorescence intensity for these new clusters is shown in Figure 4B. B, FM4-64 labeling performed at the end of the experiment revealed that the new GFP:ProSAP1 clusters were juxtaposed against functional presynaptic boutons, suggesting that new synapses had formed at these sites. All times are given in minutes. Asterisks mark identical images in $A$ and $B$. Scale bar, $5 \mu \mathrm{m}$

The recruitment dynamics of GFP:ProSAP1 and GFP:ProSAP2 to new synaptic junctions were examined by performing automated multi-site time-lapse confocal microscopy recordings as described above for NR1:GFP. Twenty new synaptic clusters of GFP:ProSAP1 and 25 of GFP:ProSAP2 were observed to form in 20 and 10 experiments, respectively. Here too, new synaptic GFP: ProSAP1 and GFP:ProSAP2 clusters appeared to form gradually over $\sim 30-40 \mathrm{~min}$ from the moment they first were observed. This is exemplified for ProSAP1 in Figure 6A, in which the formation of two new adjacent GFP:ProSAP1 clusters is shown. As illustrated in a more quantitative manner in Figure $4 B$, the fluorescence intensity of these new clusters increased gradually and 
rather monotonically with time. FM4-64 labeling performed at the end of the time-lapse recording revealed that these new clusters were juxtaposed against functional presynaptic boutons (Fig. $6 B)$, confirming the synaptic identity of these new GFP:ProSAP1 clusters.

The expression levels of both GFP:ProSAP1 and GFP:ProSAP2 were highly variable, and a tendency for overexpression was observed (60-150\%). Because overexpression of Shank1 (a third member of the Shank/ProSAP family not examined here) was shown to affect synaptic structure strongly (Sala et al., 2001), only neurons with minimal expression levels were included in our analysis. Interestingly, however, we noted that neurons with high overexpression levels seemed to have more nonsynaptic, brightly fluorescent puncta, some of which appeared to move slowly $(<0.03 \mu \mathrm{m} / \mathrm{sec})$, mainly in a centripetal direction, occasionally merging into larger structures or splitting into smaller ones. This phenomenon was much less apparent in cells with low GFP:ProSAP expression levels and thus may be primarily a result of abnormally high intracellular ProSAP levels. Although the occasional merging of smaller clusters into larger ones would be consistent with the formation of new PSDs from modular transport packets, the very low velocities of such clusters and the limited distances they traveled (a few micrometers) make it unlikely that these events represented the formation of new PSDs from some form of bona fide ProSAP transport particle (see also Marrs et al., 2001).

GFP:ProSAP (both ProSAP1 and ProSAP2) displayed additional forms of complex dynamics. For example, relatively high levels of diffuse GFP:ProSAP often were seen within dendritic growth cones; on several occasions we observed the gradual coalescence of this diffuse fluorescence into bright clusters left behind the advancing growth cone on the newly formed dendritic segment. FM4-64 labeling or retrospective immunohistochemistry for synapsin I indicated that in most cases these new clusters were associated with a presynaptic counterpart. Conversely, we observed bright dendritic GFP:ProSAP clusters that gradually became dimmer until they disappeared entirely. We suspect that the complex dynamics displayed by ProSAPs may stem from their numerous interactions with multiple synaptic molecules, the actin cytoskeleton, and possibly from rapid dendritic protein synthesis (Sheng and Kim, 2000) and degradation through the ubiquitin-proteasome system (Ehlers, 2003). In conclusion, these experiments indicate that ProSAP1 and ProSAP2 are recruited to nascent postsynaptic sites in a gradual manner from diffuse sources and with no particular involvement of large and discrete transport packets.

\section{Fluorescence recovery after photobleaching of NR1:GFP and GFP:ProSAP}

The time-lapse experiments described so far did not reveal the existence of highly mobile large ProSAP or NR1 transport packets within dendrites. However, it remained possible that such packets were obscured by the considerable diffuse fluorescence displayed by dendrites expressing GFP:ProSAPs and NR1:GFP. To examine this possibility, we used high-intensity laser light to bleach dendritic segments of neurons expressing GFP:ProSAP1, GFP:ProSAP2, or NR1:GFP and used time-lapse confocal microscopy to examine whether the bleached segments were invaded by fluorescent transport packets from dendritic segments outside the bleached regions.

One such experiment is shown in Figure 7. Here a major dendrite of a GFP:ProSAP1-expressing neuron was bleached until the diffuse fluorescence was decreased to $\sim 15 \%$ of the original
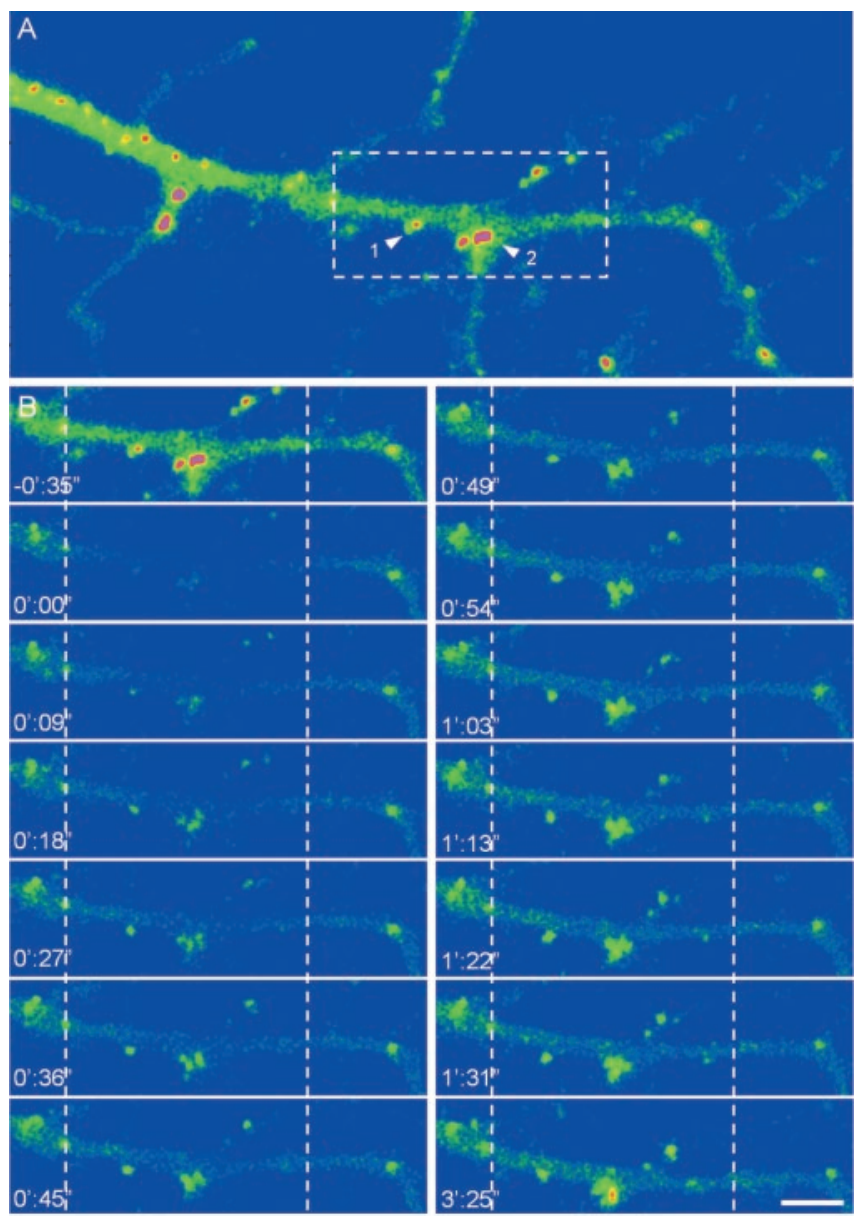

Figure 7. Photobleaching of diffuse GFP:ProSAP1 fluorescence does not reveal a cryptic poo of ProSAP1 transport particles. A, Dendritic segment of a neuron expressing GFP:ProSAP1. Note the diffuse fluorescence as well as the bright puncta of synaptic GFP:ProSAP1. Fluorescence intensity is coded in pseudocolor as in Figure 3. $B$, The region enclosed by a rectangle in $A$ was scanned by high-intensity $488 \mathrm{~nm}$ laser light for $\sim 20 \mathrm{sec}$, and images were obtained thereafter at 4.5 sec intervals (only every second image is shown here). No discernible mobile puncta were observed to move into the bleached region from the unbleached segments, but rapid recovery of GFP:ProSAP1 was observed at existing synaptic sites. The recovery time course for the numbered clusters in $A$ (arrowheads) is shown in Figure $9 A$. The bottom frame is the last image of this time-lapse sequence. The vertical dashed lines demarcate the borders of the bleached region. All times are given in minutes and seconds. Scale bar, $5 \mu \mathrm{m}$.

levels. Time-lapse recordings performed at $4.5 \mathrm{sec}$ intervals failed to reveal mobile fluorescent transport packets moving into the bleached segment (Fig. 7B). Interestingly, PSD-associated clusters of GFP:ProSAP1 within the bleached segment recovered rapidly (see Fig. 9A), suggesting that ProSAP1 can be recruited to existing synaptic sites from diffuse, nonparticulate pools. Furthermore, significant decreases in GFP:ProSAP1 fluorescence (both PSD-associated and diffuse) were observed in regions outside the bleached region, which is consistent with a rapid exchange of ProSAP1 with such diffuse pools. In seven experiments (4 with GFP:ProSAP1 and 3 with GFP:ProSAP2) no mobile fluorescent puncta were observed to move out of the unbleached regions into the bleached segments, arguing against a cryptic pool of ProSAP transport particles.

Similar experiments performed with NR1:GFP (Fig. 8) as well as SAP90/PSD-95:GFP (data not shown) also failed to reveal cryptic pools of highly mobile fluorescent puncta ( 6 and 4 experiments, respectively) within the bleached segment (regardless of image collection rate), although here, in agreement with a previ- 

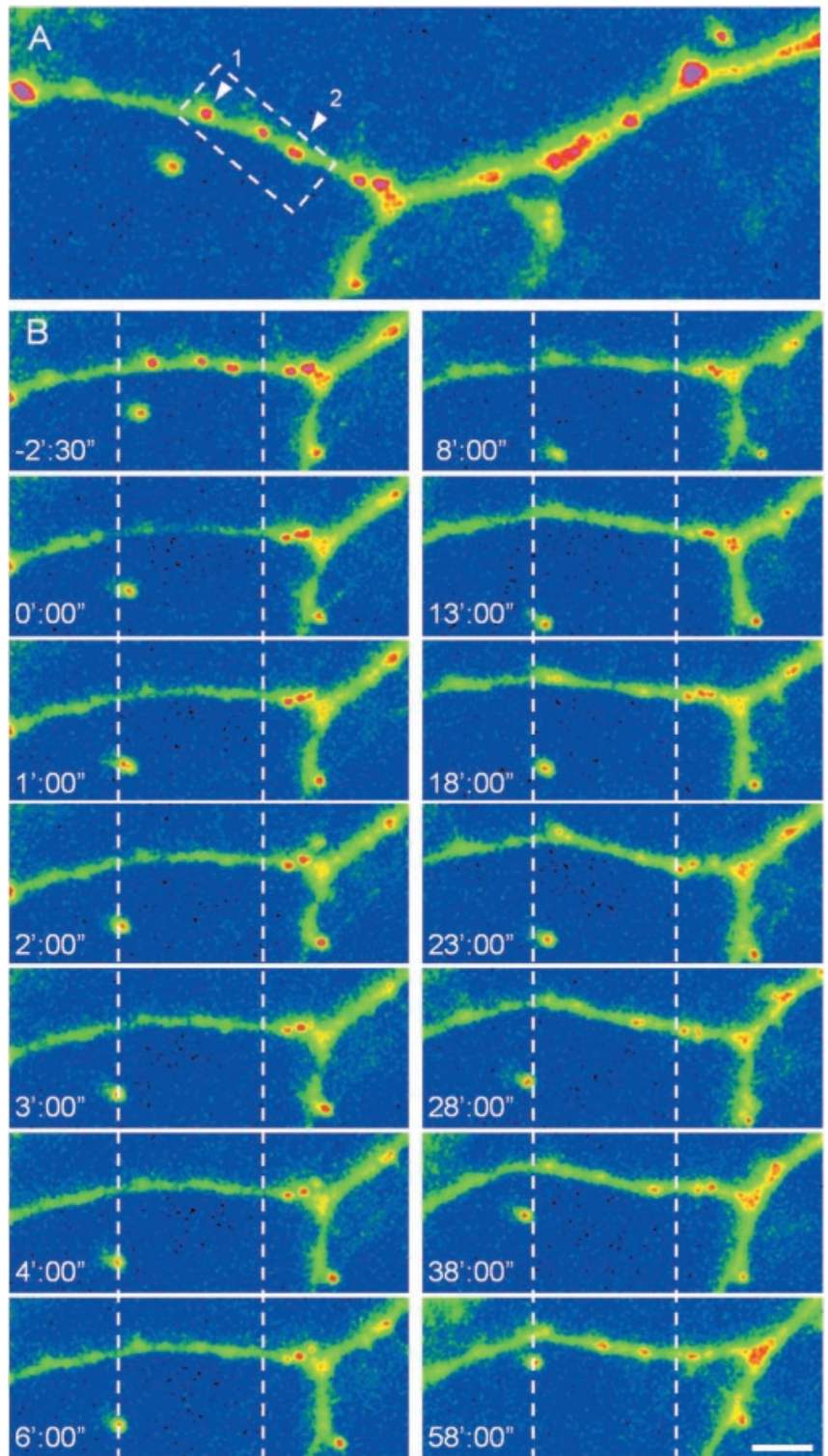

Figure 8. Photobleaching of diffuse NR1:GFP fluorescence does not reveal a cryptic pool of NR1 transport particles. A, Dendritic segment of a neuron expressing NR1:GFP. Note the diffuse fluorescence as well as the bright puncta of synaptic NR1:GFP. Fluorescence intensity is coded in pseudocolor as in Figure 3. $B$, The region enclosed by a rectangle in $A$ was scanned by highintensity $488 \mathrm{~nm}$ laser light for $\sim 20 \mathrm{sec}$, and images were obtained thereafter at 1 min intervals (for the first $8 \mathrm{~min}$ ) and at $5 \mathrm{~min}$ intervals later on. No discernible mobile puncta were observed to move into the bleached region from the unbleached segments, but a gradual recovery of NR1:GFP was observed at existing synaptic sites. The recovery time course for the numbered clusters in $A$ (arrowheads) is shown in Figure $9 B$. The bottom frame is the last image of this time-lapse sequence. The vertical dashed lines demarcate the borders of the bleached region. All times are given in minutes and seconds. Scale bar, $5 \mu \mathrm{m}$.

ous report (Okabe et al., 2001b), the recovery rates of PSDassociated fluorescence were much slower than those observed for ProSAPs (Fig. 9B).

\section{Recruitment of the $\mathrm{AZ}$ molecule Bassoon to new}

presynaptic sites

Our experiments concerning the recruitment of NR1, ProSAP1, ProSAP2 (this study), and SAP90/PSD-95 (Bresler et al., 2001) indicated that PSD assembly occurs in a gradual manner, with no evidence for the involvement of large and readily observable PSD transport particles. On the other hand, it has been suggested pre-
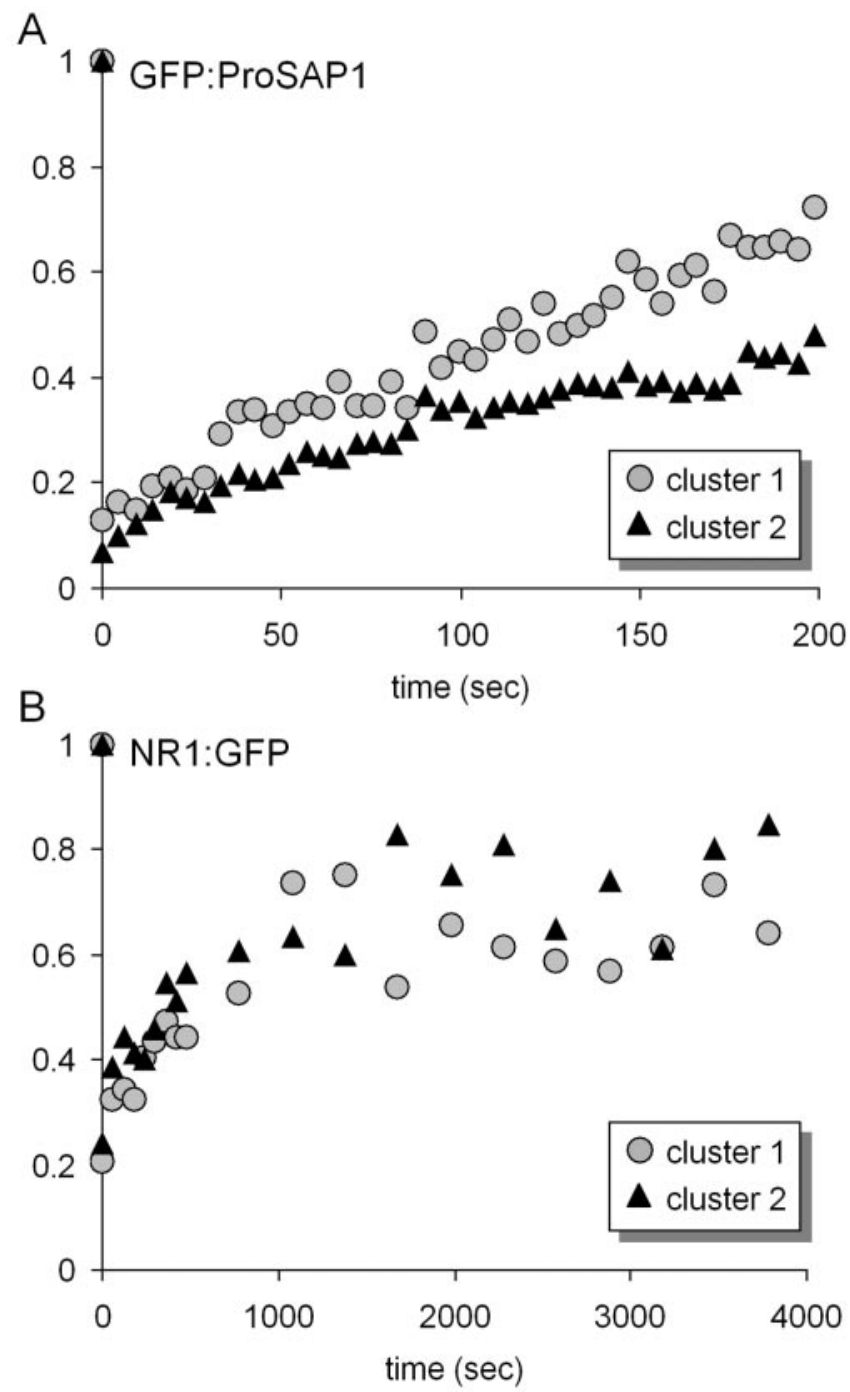

Figure 9. Time course of fluorescence recovery at photobleached GFP:ProSAP1 and NR1:GFP clusters. A, Recovery time course of GFP:ProSAP1 clusters shown in Figure 7. B, Recovery time course of NR1:GFP clusters shown in Figure 8. Fluorescence is given as a fraction of the nominal fluorescence of each cluster before the photobleaching procedure. Cluster numbers refer to the labels in Figures 7 and 8 , respectively.

viously that AZs may be formed from a small number (2-3) of modular transport vesicles (PTVs) that fuse with the presynaptic plasma membrane at new axodendritic contact sites (Zhai et al., 2001; Shapira et al., 2003). Are AZ molecules indeed recruited to nascent synaptic sites from readily observable transport particles? To examine this possibility, we performed similar experiments in which we recorded the recruitment dynamics of Bassoon, a huge $(420 \mathrm{kDa})$ and prominent presynaptic molecule that is one of a small number of AZ cytomatrix-specific proteins identified so far (tom Dieck et al., 1998; Dresbach et al., 2001). To that end we expressed a GFP-tagged variant of Bassoon (GFP:Bsn95-3938) that was shown previously to be targeted correctly to presynaptic sites (Dresbach et al., 2003). Because expression levels of GFP: Bsn95-3938 were somewhat variable, only neurons with low-tomoderate expression levels of this molecule $(<50 \%$ overexpression of total Bassoon) were studied. In agreement with our previous observations, in which a different Bassoon construct was used (Shapira et al., 2003), the expression pattern of GFP: Bsn95-3938 in axons of cultured hippocampal neurons was 

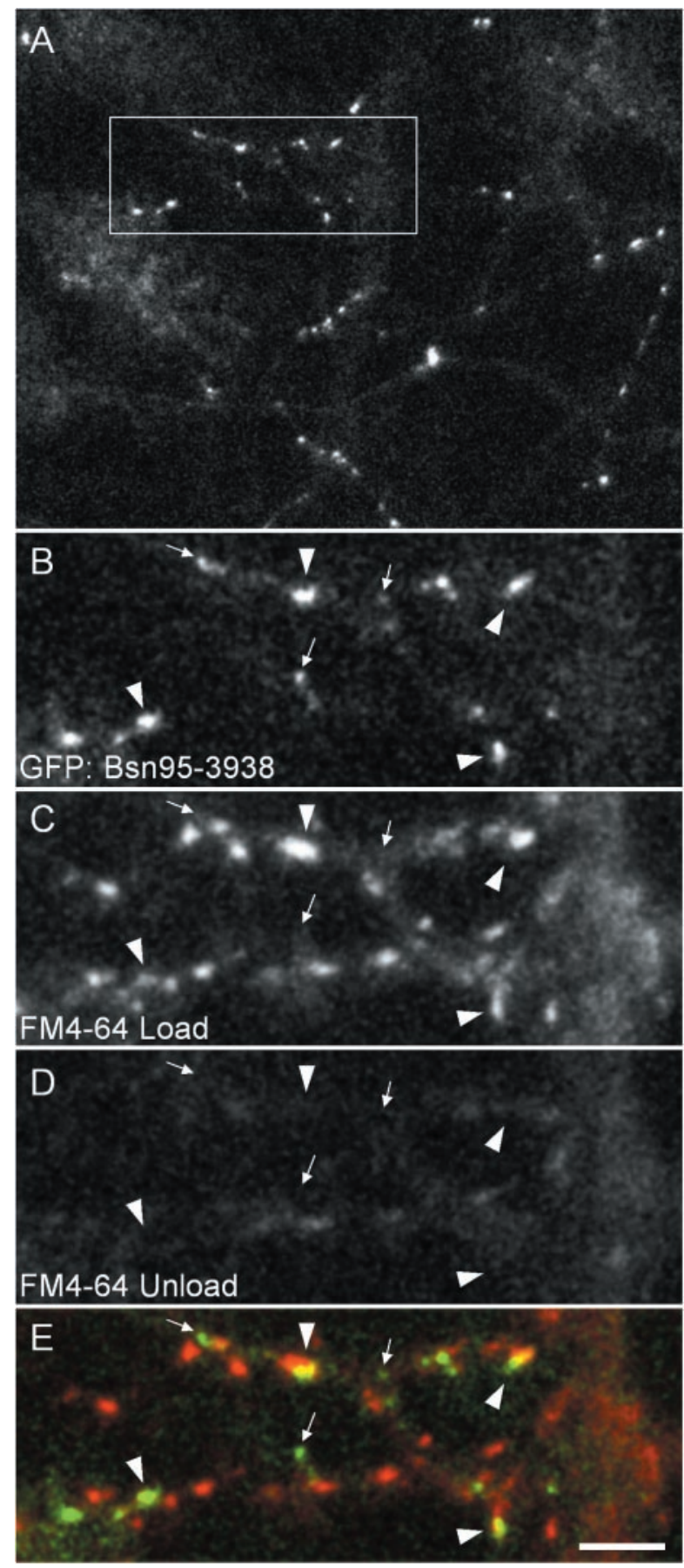

Figure 10. Expression pattern of GFP:Bsn95-3938. A, GFP:Bsn95-3938 displays a punctate expression pattern in axons. $B$, Higher magnification of the region enclosed in the rectangle in $A$. $C$, D, Same region after the labeling of functional presynaptic boutons with FM4-64. E, Many of the GFP:Bsn95-3938 puncta (green) colocalized with sites of FM4-64 uptake and release (red) as indicated by the arrowheads, indicating that these resided at functional AZs. In addition, a population of smaller GFP:Bsn95-3938 puncta did not colocalize with functional synaptic vesicle release sites (arrows). Many of these were highly mobile, moving at velocities of up to 0.4 $\mu \mathrm{m} / \mathrm{sec}$. Scale bar, $5 \mu \mathrm{m}$

punctate (Fig. 10A). Whereas the larger GFP:Bsn95-3938 puncta were usually stable and associated with functional sites of SV recycling (Fig. 10B-E), many of the smaller and dimmer puncta displayed rapid longitudinal movements along axons (peak rates, $0.4 \mu \mathrm{m} / \mathrm{sec}$; see also Shapira et al., 2003). Detailed examination of such time-lapse sequences (performed at 3-10 min intervals) re- vealed the occasional formation of new large GFP:Bsn95-3938 clusters, which with fixation and immunolabeling were found to be positive for the presynaptic molecule synapsin I. Each of these new clusters had appeared to form by the merging of a small number (2-3 in $62 \%$ of the cases) of mobile GFP:Bsn95-3938 puncta ( $n=30 ; 9$ different experiments). In contrast to what we observed for postsynaptic molecules, we did not detect the formation of new Bassoon puncta in a gradual manner, and the formation of apparently new synaptic Bassoon clusters always was preceded by the presence of smaller but detectable mobile GFP:Bsn95-3938 puncta in their immediate vicinity. Thus we could not rule out the possibility that the apparently new AZs were, in fact, preexisting presynaptic boutons that somehow had congregated into what appeared to be a single new structure.

To distinguish new presynaptic boutons from preexisting ones, we prelabeled the initial population of functional presynaptic boutons using FM4-64 and field stimulation as described above. Afterward, time-lapse recordings of GFP:Bsn95-3938 were performed for $45 \mathrm{~min}$, during which images were obtained every 3 min. Finally, a second round of FM4-64 labeling was performed, which allowed us to detect newly formed presynaptic boutons (Vardinon-Friedman et al., 2000).

The formation of one such apparently new presynaptic bouton is shown in Figure 11A. Discrete GFP:Bsn95-3938 puncta appear to move along the axon, several of them finally coming to rest at a site that initially had displayed no activity-induced FM4-64 uptake (Fig. 11B). After the second FM4-64 labeling procedure a marked capacity for activity-induced exocytosis and endocytosis was observed at the same site (Fig. 11C), suggesting that a new functional AZ had formed, presumably preceded by the fusion of a small number of PTVs with the axonal membrane. Indeed, a quantitative analysis of GFP:Bsn95-3938 fluorescence intensities over this period (Fig. $4 C$ ) reveals "stepwise" intensity changes at this site that are consistent with the recruitment of two to three PTVs to this new synaptic site.

Given the small number of new synapses that formed over the limited duration of the time-lapse sessions and the fact that $<1 \%$ of the axons expressed GFP:Bsn95-3938, the likelihood of locating such events was quite low (Vardinon-Friedman et al., 2000). Nevertheless, we managed to record seven such events in seven separate experiments (14 fields of view). In all cases the overall pattern was similar; unlike the gradual accumulation we observed for postsynaptic proteins, Bassoon seemed to be recruited to new synaptic sites via discernible mobile particles. In most cases one particle would stop at the future synaptic site; after a while (3-12 min; average, $6 \pm 3.2 \mathrm{~min}$ ) another would merge with it, which may indicate that the particles (presumably PTVs) had fused with the axonal plasma membrane. The time measured from the first detection of a stationary GFP:Bsn95-3938 at a future synaptic site to the acquisition of a capacity for activity-evoked endocytosis and exocytosis (as revealed by the second FM4-64 labeling procedure) ranged from 15 to $45 \mathrm{~min}$, in agreement with previous studies based on retrospective immunohistochemistry (Vardinon-Friedman et al., 2000; Zhai et al., 2001). In the seven events that we recorded, three new synaptic Bassoon clusters had appeared to form from two mobile puncta, two clusters from three mobile puncta, and two clusters from a number of puncta (3-5) that we could not determine exactly. It is worth noting, however, that in many instances we observed puncta that seemingly had been stabilized at specific sites suddenly move away from these sites and resume their movement along axons (Fig. 11 A, top panels)

We previously have used quantitative immunohistochemistry 

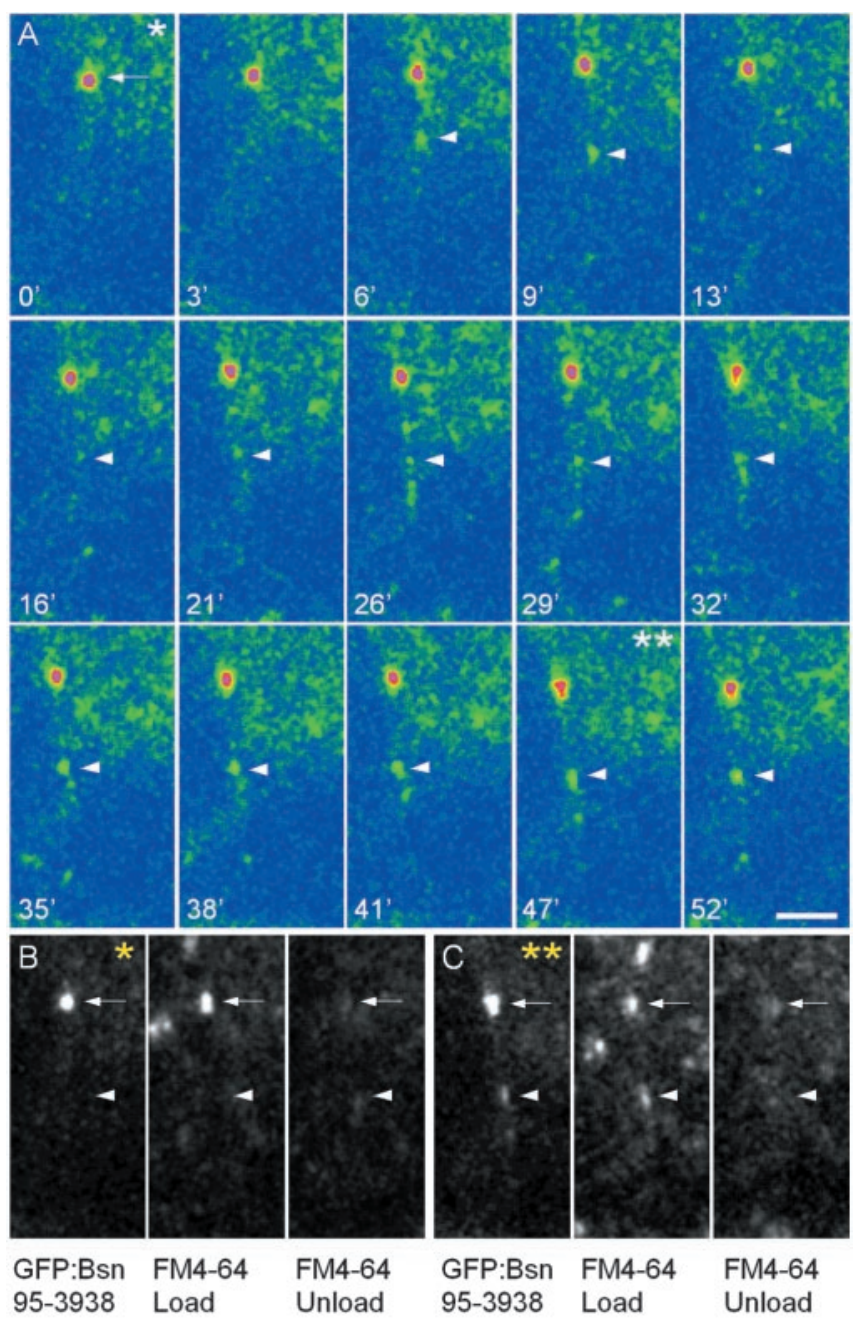

Figure 11. Formation of new functional AZs is preceded by the recruitment of mobile GFP: Bsn95-3938 particles. A, Time lapse of an axon of a neuron expressing GFP:Bsn95-3938. At the beginning of the time lapse a single large and static GFP:Bsn95-3938 cluster is seen (arrow) at a site displaying a capacity for activity-evoked FM4-64 uptake and release (B), suggesting that it resides at a functional AZ. Then 6 min into the time lapse a new cluster appears that subsequently breaks up into two clusters ( $t=13 \mathrm{~min}$ ). One of these remains at the original site (arrowheads). At $t=26 \mathrm{~min}$, additional clusters arrive, some of which merge with the first cluster ( $t=35 \mathrm{~min}$ ). A second round of FM4-64 labeling $(C$ indicates that a new functional presynaptic site has formed at the same location. Quantitative measurements of the fluorescence changes at this site indicate that the formation of the new functional presynaptic site has been preceded by the recruitment of two to three unitary amounts of GFP:Bsn95-3938 (Fig. 4C). All times are given in minutes. Asterisks mark identical images in $A$ and $B$ or in $A$ and C. Scale bar, $5 \mu \mathrm{m}$.

to compare the amounts of three AZ molecules (Bassoon, Piccolo, and Rim) in presynaptic boutons and in small nonsynaptic puncta that were presumed to be PTVs (Shapira et al., 2003). This analysis indicated that the AZ molecules Bassoon, Piccolo, and Rim might be recruited to nascent synaptic sites by means of small numbers $(<5)$ of modular transport particles, namely PTVs. However, the amounts of Bassoon, Piccolo, and Rim at synapses were distributed rather broadly and did not exhibit unambiguous peaks, which was not unexpected given that the PTVassociated amounts of these proteins also were distributed quite broadly. Unlike the previous study, however, in which bouton populations were studied, the current study examined the formation of individual boutons; thus the stepwise additions of a small number of AZ material units usually were not obscured by the variability in population step size.
In conclusion, these experiments support previous suggestions (Zhai et al., 2001; Shapira et al., 2003) that the AZ molecule Bassoon (and, by inference, additional PTV-associated AZ molecules) may be recruited to nascent synaptic sites by means of small numbers of modular transport particles. Furthermore, these results suggest that the imaging system and methodologies applied here are sensitive enough to detect synaptic assembly by such a mechanism. Finally, the stepwise changes in fluorescence intensity observed for GFP:Bsn95-3938 at new synaptic sites appear to be qualitatively different from the gradual increases observed for NR1, ProSAP1, and ProSAP2, suggesting that the mechanisms by which Bassoon is recruited to synaptic sites are qualitatively different from those underlying the recruitment of the postsynaptic molecules that were examined here.

\section{Kinetics of PSD molecule recruitment to nascent postsynaptic sites}

The formation of new synaptic clusters of all three PSD molecules studied here seemed to occur by a gradual recruitment of fluorescent material from undefined, diffuse sources. To determine the kinetics of these recruitment processes, we quantified the changes in the total fluorescence within square boxes $(\sim 1 \times 1$ $\mu \mathrm{m}$ ) centered on the new clusters (see also Bresler et al., 2001). When data from all recorded events were normalized and pooled together for each of the molecules studied here (see Materials and Methods), the average recruitment kinetics of these molecules emerged (Fig. 12). The recruitment process for all molecules was found to be quite rapid, seemed to plateau within $\sim 1 \mathrm{hr}$, and could be fit with single exponentials with time constants of $\sim 13$, 12, and $14 \mathrm{~min}$ for NR1, ProSAP1, and ProSAP2, respectively. In comparison, the mean intensity of preexisting clusters did not change much over time, except for a slight time-dependent decrease probably caused by photobleaching. Strikingly, when all of the data were plotted together and combined with similar data concerning the recruitment kinetics of SAP90/PSD-95 (Bresler et al., 2001), all points seemed to fall on a single curve (Fig. 12G), indicating that ProSAP1, ProSAP2, NR1, and SAP90/PSD-95 are recruited to nascent postsynaptic sites with remarkably similar kinetics.

\section{Discussion}

Here we examined the recruitment of the PSD molecules NR1, ProSAP1, and ProSAP2 to nascent synaptic junctions formed among hippocampal neurons in culture. The recruitment of all three molecules occurred in gradual manner and with very similar kinetics, with no obvious involvement of discernible transport particles. In contrast, the $\mathrm{AZ}$ molecule Bassoon was recruited to new presynaptic sites from a small number of mobile packets, presumably PTVs. These findings indicate that the assembly mechanisms of AZs and PSDs may be fundamentally different.

\section{Involvement of modular transport packets in PSD assembly} In a recent study Washbourne and colleagues (2002) expressed fluorescently tagged subunits of NMDA and AMPA receptors (NR1 and GluR1) in cultured neurons and examined their recruitment to new axodendritic contact sites. NR1 and GluR1 were observed to be transported to nascent synapses as large particles, and it was suggested that these constitute modular glutamate receptor transport packets. Here, however, we found no compelling evidence for the involvement of such packets in PSD assembly. One possible resolution of these apparently contradictory findings may be found in the different preparations that were 

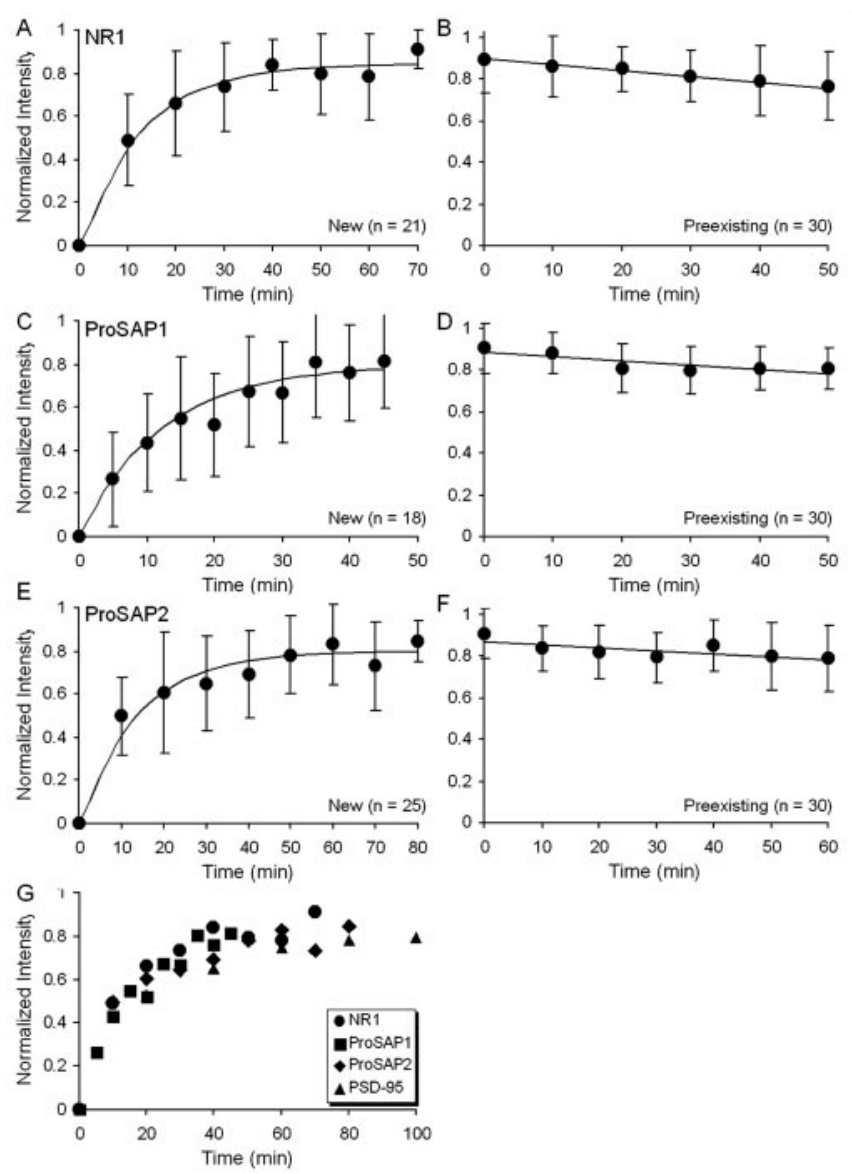

Figure 12. PSD molecules are recruited to new postsynaptic sites with similar kinetics. The average time course of PSD molecule recruitment to new synaptic sites has been determined by normalizing and pooling together data from all recorded events for NR1:GFP ( $A$ ), GFP:ProSAP1 $(C)$, and GFP:ProSAP2 $(E)$, as described in Materials and Methods. Data are provided as averages and SDs (error bars) of normalized fluorescence intensities. The solid lines in these panels are single exponentials with time constants of 13, 12, and 14 min for NR1:GFP, GFP:ProSAP1, and GFP:ProSAP2, respectively. Fluorescence intensities of 30 preexisting clusters of NR1:GFP $(B)$, GFP:ProSAP1 (D), and GFP:ProSAP2 ( $F$ ) measured over similar periods do not show significant changes except for small gradual decreases, probably resulting from photobleaching. $G$, The average recruitment kinetics for NR1:GFP, GFP:ProSAP1, and GFP:ProSAP2 of $A, C$, and $E$ plotted together with previously published data for SAP90/PSD-95 (Bresler et al., 2001). Note the very similar recruitment kinetics displayed by all four PSD molecules.

used. Our studies were performed in hippocampal neurons obtained from postnatal rats and examined after $8-13 \mathrm{~d}$ in vitro, whereas Washbourne and colleagues performed their study in cortical neurons obtained from newborn rats and grown in vitro for much shorter periods (3-4 d). In our hands cortical neurons maintained in culture for $3 \mathrm{~d}$ have very few synapses (as judged by synapsin I staining) and very little synapse-specific NR1 or GluR1 staining (data not shown). This would seem to indicate that our preparations are substantially different, making a direct comparison of our results somewhat difficult. It thus remains possible that the recruitment of PSD molecules to synapses formed at very early stages of neuronal differentiation is qualitatively different from that observed later on.

NMDA receptor subunits are integral membrane proteins and thus must be shuttled to the dendritic membrane on some vesicular intermediate. Here, however, we were not able to detect these vesicles. Because the dimensions of these vesicles are almost certainly below the resolution of light microscopy, the most likely interpretation is that these vesicular intermediates were too dim or spaced too closely (or both) to be detected in our system. We certainly would have been able to detect such vesicular structures if their fluorescence intensities were within $20-30 \%$ of those of synaptic NR1:GFP clusters (in particular after photobleaching the background fluorescence, as in Fig. 8). Yet as none was detected, this suggests that NR1:GFP is carried on many small vesicular intermediates, each carrying a small fraction of the amount of NR1 found at typical PSDs. In comparison, quantitative analysis suggests that the material carried on just a few (1-4) PTVs may be sufficient for the formation of a new AZ (Shapira et al., 2003). Similarly, the SV content of individual boutons was observed to be equivalent to the content of one to four SV transport packets (Ahmari et al., 2000).

Another possibility is that PSD molecule transport rates during the experiments were very low or nonexistent. However, it would be difficult to reconcile this possibility with the fact that as soon as $24 \mathrm{hr}$ from transfection practically all PSDs (as detected by immunohistochemistry) along the entire dendritic tree of the transfected neuron displayed punctate GFP fluorescence. Furthermore, the recovery of fluorescence at photobleached PSDs (Figs. 7-9) also argues against the possibility that little or no PSD molecule transport was occurring.

A final possibility that should be considered is that highly mobile transport particles may have been missed at the relatively low image collection rates used here ( 1 image every 5-10 min). It should be noted, however, that the image collection rates ultimately used were based on a long series of preliminary experiments in which neurons expressing NR1:GFP, GFP:ProSAP1, or GFP:ProSAP2 were imaged at various rates, as high as 1 image/10 sec. Because nothing in particular was observed to occur at much higher sampling rates (no highly mobile particles, no rapid formation of new PSD molecule clusters), we reduced image collection rates to avoid unnecessary photobleaching.

Dendritic vesicles containing NR1 and NR2B were observed to be associated with the molecular motor KIF17, and it was suggested that KIF17 serves to shuttle NMDA receptors to postsynaptic sites (Setou et al., 2000). Imaging of fluorescently tagged KIF17 revealed, however, that these vesicles were restricted to dendritic shafts and did not enter PSDs (Guillaud et al., 2003). Furthermore, their average velocities $(0.76 \mu \mathrm{m} / \mathrm{sec})$ were an order of magnitude greater than those of the NR1 packets described by Washbourne and colleagues, $\sim 0.07 \mu \mathrm{m} / \mathrm{sec}(2002)$. Finally, Guillaud and colleagues (2003) reported that their attempts to visualize the transport of fluorescently tagged NR2B were not successful. Thus these vesicles may have functions other than the transport of NMDA receptors to PSDs, such as endoplasmic reticulum to Golgi trafficking (Horton and Ehlers, 2003) or insertion of NMDA receptors into dendritic membranes at extrasynaptic sites (see below).

In addition to synaptic clusters of GFP-tagged PSD molecules, we consistently observed clusters that did not colocalize with other synaptic markers. Because similar proportions of nonsynaptic puncta were observed by immunohistochemistry in naive neurons, this was probably not an artifact of exogenous molecule expression (although high overexpression levels often were associated with more nonsynaptic clusters). What are these clusters? Although it would be logical to assume that these are transport packets of some sort, most nonsynaptic clusters were no more mobile than synaptic clusters, questioning their role in dendritic transport. Several alternative explanations for these nonsynaptic clusters can be envisaged. They could represent sites of aborted synaptogenesis, leftovers of synaptic elimination, residual structures remaining after the death of presynaptic neurons, sites of 
dendritic protein synthesis, or spontaneous PSD molecule clustering at nonsynaptic sites (see below).

\section{Gradual assembly of postsynaptic densities}

An alternative to PSD assembly from modular transport packets is an assembly process based on the gradual recruitment of postsynaptic molecules from local, diffuse pools. Experiments described here and elsewhere are in good agreement with this mode of PSD assembly. First, all PSD molecules examined here displayed a gradual recruitment pattern. Second, elimination of diffuse dendritic fluorescence by photobleaching did not reveal cryptic pools of highly mobile PSD transport particles (Figs. 7-9). Third, studies concerning the de novo formation of SAP90/ PSD95 and PSD-Zip45/Homer 1c synaptic clusters (Bresler et al., 2001; Marrs et al., 2001; Okabe et al., 2001a,b) indicate that this process is gradual as well.

Surprisingly, the recruitment kinetics of all of the PSD molecules examined here (NR1, ProSAP1, ProSAP2) and elsewhere (SAP90/PSD-95) were remarkably similar (Fig. 12G). Although this could be taken as evidence for co-recruitment from precursor vesicles, other equally plausible mechanisms could lead to the same result. One possibility is that these molecules are recruited sequentially, with the recruitment of each molecule being dependent on the prior recruitment of the molecules to which it binds. In this case the rate of PSD formation could be dictated by a relatively slow recruitment rate of some upstream molecule.

A second possibility is that the recruitment of PSD molecules to nascent postsynaptic sites is a two-step process in which (1) PSD molecules assemble into multi-molecular complexes at the dendritic membrane, and (2) these diffusely distributed complexes, free to move laterally along the membrane, thereafter are confined, trapped, or cross-linked at new axodendritic contact sites. According to this model, integral membrane proteins are inserted into the dendritic membrane at extrasynaptic locations via constitutive or regulated mechanisms while cytosolic molecules form complexes with these molecules en route to or at the dendritic membrane. Trapping/cross-linking mechanism(s) acting at nascent axodendritic contact sites would lead to gradual PSD growth by synchronous recruitment of multiple postsynaptic molecules and would constitute the rate-limiting step that governs the kinetics of PSD molecule recruitment. This model is similar to the "diffusion-retention" model proposed to underlie clustering of acetylcholine receptors, glycine receptors, and glutamate receptors at neuromuscular junctions, glycinergic synapses, and glutamatergic synapses, respectively (for review, see Choquet and Triller, 2003), except that here the retaining molecules also are being confined to nascent postsynaptic sites by some rate-limiting upstream processes.

This two-step model for PSD assembly is in good agreement with recent studies concerning postsynaptic molecule trafficking. For example, targeting of AMPA and NMDA receptors to the dendritic membrane appears to be mechanistically distinct from the clustering of these molecules at postsynaptic sites (Chen et al., 2000; Steigerwald et al., 2000; Passafaro et al., 2001; Prybylowski et al., 2002; Schnell et al., 2002). NMDA, AMPA, and metabotropic glutamate receptors move continuously in and out of the PSD, where they are trapped periodically for various durations (Borgdorff and Choquet, 2002; Serge et al., 2002; Tovar and Westbrook, 2002) (see also Barry and Ziff, 2002; Inoue and Okabe, 2003; Wenthold et al., 2003). Scaffolding molecules such as SAP90/PSD-95, SAP97, and SAP102 may form complexes with glutamate receptors long before these reach postsynaptic sites (El-Husseini et al., 2000; Sans et al., 2001, 2003) (see also Thomas et al., 2000). Still, because our data are consistent with both models, further work is necessary to determine which (if any) is more correct.

\section{Differences between PSD and AZ assembly}

In our consideration of mechanisms used in PSD and AZ assembly, it is worth bearing in mind the constraints imposed by the roles and locations of these structures. Postsynaptic compartments are usually dendritic and, therefore, relatively close to somatic (and dendritic) biosynthetic centers, reducing the necessity of elaborate delivery mechanisms. In terms of function, dendrites must respond to multiple axonal signals and deliver appropriate complements of postsynaptic molecules to match the identities of their axonal counterparts (Craig and Boudin, 2001). Furthermore, synaptic activity and additional stimuli rapidly alter the composition of individual PSDs, and in particular their AMPA as well their NMDA receptor content, by mechanistically distinct pathways (Barry and Ziff, 2002; Carroll and Zukin, 2002; Malinow and Malenka, 2002; Inoue and Okabe, 2003; Wenthold et al., 2003). Thus there is basically no reason to expect that PSDs would be preassembled at remote sites and then shuttled to their final destinations.

Presynaptic sites, on the other hand, usually are formed at remote axonal locations, far from the somatic biosynthetic center, and usually secrete only one type of neurotransmitter. The "prepacking" of multiple presynaptic components into small numbers of modular units thus would be appropriate here, because it could expedite the sorting of multiple presynaptic components into axons and reduce potential problems associated with the separate transport of numerous critical components over long distances. Indeed, this seems to be a common theme in a number of studies concerning different aspects of presynaptic differentiation (Kraszewski et al., 1995; Nakata et al., 1998; Ahmari et al., 2000; Zhai et al., 2001; Sytnyk et al., 2002; Shapira et al., 2003). Although it remains to be seen whether the proposed differences between PSD and AZ assembly hold true for all of the components involved, our study strongly supports this emerging principle.

\section{References}

Ahmari SE, Buchanan J, Smith SJ (2000) Assembly of presynaptic active zones from cytoplasmic transport packets. Nat Neurosci 3:445-451.

Barry MF, Ziff EB (2002) Receptor trafficking and the plasticity of excitatory synapses. Curr Opin Neurobiol 12:279-286.

Basarsky TA, Parpura V, Haydon PG (1994) Hippocampal synaptogenesis in cell culture: developmental time course of synapse formation, calcium influx, and synaptic protein distribution. J Neurosci 14:6402-6411.

Böckers TM, Mameza MG, Kreutz MR, Bockmann J, Weise C, Buck F, Richter D, Gundelfinger ED, Kreienkamp HJ (2001) Synaptic scaffolding proteins in rat brain. Ankyrin repeats of the multidomain Shank protein family interact with the cytoskeletal protein $\alpha$-fodrin. J Biol Chem 276:40104-40112.

Bockmann J, Kreutz MR, Gundelfinger ED, Boeckers TM (2002) ProSAP/ Shank postsynaptic density proteins interact with insulin receptor tyrosine kinase substrate IRSp53. J Neurochem 83:1013-1017.

Boeckers TM, Kreutz MR, Winter C, Zuschratter W, Sanmarti-Vila L, Wex H, Langnaese K, Bockmann J, Garner CC, Gundelfinger ED (1999a) Proline-rich synapse-associated protein-1/cortactin binding protein 1 (ProSAP1/ CortBP1) is a PDZ domain protein highly enriched in the postsynaptic density. J Neurosci 19:6506-6518.

Boeckers TM, Winter C, Smalla KH, Kreutz MR, Bockmann J, Seidenbecher C, Garner CC, Gundelfinger ED (1999b) Proline-rich synapseassociated proteins ProSAP1 and ProSAP2 interact with synaptic proteins of the SAPAP/GKAP family. Biochem Biophys Res Commun 264:247-252.

Boeckers TM, Bockmann J, Kreutz MR, Gundelfinger ED (2002) ProSAP/ 
Shank proteins-a family of higher order organizing molecules of the postsynaptic density with an emerging role in human neurological disease. J Neurochem 81:903-910.

Borgdorff AJ, Choquet D (2002) Regulation of AMPA receptor lateral movements. Nature 417:649-653.

Bresler T, Ramati Y, Zamorano PL, Zhai R, Garner CC, Ziv NE (2001) The dynamics of SAP90/PSD-95 recruitment to new synaptic junctions. Mol Cell Neurosci 18:149-167.

Carroll RC, Zukin RS (2002) NMDA-receptor trafficking and targeting: implications for synaptic transmission and plasticity. Trends Neurosci 25:571-577.

Chen L, Chetkovich DM, Petralia RS, Sweeney NT, Kawasaki Y, Wenthold RJ, Bredt DS, Nicoll RA (2000) Stargazin regulates synaptic targeting of AMPA receptors by two distinct mechanisms. Nature 408:936-943.

Choquet D, Triller A (2003) The role of receptor diffusion in the organization of the postsynaptic membrane. Nat Rev Neurosci 4:251-265.

Cochilla AJ, Angleson JK, Betz WJ (1999) Monitoring secretory membrane with FM1-43 fluorescence. Annu Rev Neurosci 22:1-10.

Craig AM, Boudin H (2001) Molecular heterogeneity of central synapses: afferent and target regulation. Nat Neurosci 4:569-578.

Dingledine R, Borges K, Bowie D, Traynelis SF (1999) The glutamate receptor ion channels. Pharmacol Rev 51:7-61.

Dresbach T, Qualmann B, Kessels MM, Garner CC, Gundelfinger ED (2001) The presynaptic cytomatrix of brain synapses. Cell Mol Life Sci 58:94-116.

Dresbach T, Hempelmann A, Spilker C, tom Dieck S, Altrock WD, Zuschratter W, Garner CC, Gundelfinger ED (2003) Functional regions of the presynaptic cytomatrix protein Bassoon: significance for synaptic targeting and cytomatrix anchoring. Mol Cell Neurosci 23:279-291.

Du Y, Weed SA, Xiong WC, Marshall TD, Parsons JT (1998) Identification of a novel cortactin SH3 domain-binding protein and its localization to growth cones of cultured neurons. Mol Cell Biol 18:5838-5851.

Ehlers MD (2003) Activity level controls postsynaptic composition and signaling via the ubiquitin-proteasome system. Nat Neurosci 6:231-242.

El-Husseini AE, Craven SE, Chetkovich DM, Firestein BL, Schnell E, Aoki C, Bredt DS (2000) Dual palmitoylation of PSD-95 mediates its vesiculotubular sorting, postsynaptic targeting, and ion channel clustering. J Cell Biol 148:159-172.

Garner CC, Nash J, Huganir RL (2000) PDZ domains in synapse assembly and signaling. Trends Cell Biol 10:274-280.

Garner CC, Zhai RG, Gundelfinger ED, Ziv NE (2002) Molecular mechanisms of CNS synaptogenesis. Trends Neurosci 25:243-251.

Goda Y, Davis GW (2003) Mechanisms of synapse assembly and disassembly. Neuron 40:243-264.

Guillaud L, Setou M, Hirokawa N (2003) KIF17 dynamics and regulation of NR2B trafficking in hippocampal neurons. J Neurosci 23:131-140.

Horton AC, Ehlers MD (2003) Dual modes of endoplasmic reticulum-toGolgi transport in dendrites revealed by live-cell imaging. J Neurosci 23:6188-6199.

Inoue A, Okabe S (2003) The dynamic organization of postsynaptic proteins: translocating molecules regulate synaptic function. Curr Opin Neurobiol 13:332-340.

Kennedy MB (2000) Signal-processing machines at the postsynaptic density. Science 290:750-754.

Kohrmann M, Haubensak W, Hemraj I, Kaether C, Lessmann VJ, Kiebler MA (1999) Fast, convenient, and effective method to transiently transfect primary hippocampal neurons. J Neurosci Res 58:831-835.

Kornau HC, Schenker LT, Kennedy MB, Seeburg PH (1995) Domain interaction between NMDA receptor subunits and the postsynaptic density protein PSD-95. Science 269:1737-1740.

Kraszewski K, Mundigl O, Daniell L, Verderio C, Matteoli M, De Camilli P (1995) Synaptic vesicle dynamics in living cultured hippocampal neurons visualized with CY3-conjugated antibodies directed against the lumenal domain of synaptotagmin. J Neurosci 15:4328-4342.

Laurie DJ, Seeburg PH (1994) Regional and developmental heterogeneity in splicing of the rat brain NMDAR1 mRNA. J Neurosci 14:3180-3194.

Malinow R, Malenka RC (2002) AMPA receptor trafficking and synaptic plasticity. Annu Rev Neurosci 25:103-126.

Marrs GS, Green SH, Dailey ME (2001) Rapid formation and remodeling of postsynaptic densities in developing dendrites. Nat Neurosci 4:1006-1013.
McGee AW, Bredt DS (2003) Assembly and plasticity of the glutamatergic postsynaptic specialization. Curr Opin Neurobiol 13:111-118.

Murthy VN, De Camilli P (2003) Cell biology of the presynaptic terminal. Annu Rev Neurosci 26:701-728.

Naisbitt S, Kim E, Tu JC, Xiao B, Sala C, Valtschanoff J, Weinberg RJ, Worley PF, Sheng M (1999) Shank, a novel family of postsynaptic density proteins that binds to the NMDA receptor/PSD-95/GKAP complex and cortactin. Neuron 23:569-582.

Nakanishi N, Axel R, Shneider NA (1992) Alternative splicing generates functionally distinct $N$-methyl-D-aspartate receptors. Proc Natl Acad Sci USA 89:8552-8556.

Nakata T, Terada S, Hirokawa N (1998) Visualization of the dynamics of synaptic vesicle and plasma membrane proteins in living axons. J Cell Biol 140:659-674.

Niethammer M, Kim E, Sheng M (1996) Interaction between the C terminus of NMDA receptor subunits and multiple members of the PSD-95 family of membrane-associated guanylate kinases. J Neurosci $16: 2157-2163$.

Okabe S, Miwa A, Okado H (2001a) Spine formation and correlated assembly of presynaptic and postsynaptic molecules. J Neurosci 21:6105-6114.

Okabe S, Urushido T, Konno D, Okado H, Sobue K (2001b) Rapid redistribution of the postsynaptic density protein PSD-Zip45 (Homer 1c) and its differential regulation by NMDA receptors and calcium channels. J Neurosci 21:9561-9571.

Passafaro M, Piech V, Sheng M (2001) Subunit-specific temporal and spatial patterns of AMPA receptor exocytosis in hippocampal neurons. Nat Neurosci 4:917-926.

Prange O, Murphy TH (2001) Modular transport of postsynaptic density-95 clusters and association with stable spine precursors during early development of cortical neurons. J Neurosci 21:9325-9333.

Prybylowski K, Fu Z, Losi G, Hawkins LM, Luo J, Chang K, Wenthold RJ, Vicini S (2002) Relationship between availability of NMDA receptor subunits and their expression at the synapse. J Neurosci 22:8902-8910.

Rao A, Craig AM (1997) Activity regulates the synaptic localization of the NMDA receptor in hippocampal neurons. Neuron 19:801-812.

Rao A, Kim E, Sheng M, Craig AM (1998) Heterogeneity in the molecular composition of excitatory postsynaptic sites during development of hippocampal neurons in culture. J Neurosci 18:1217-1229.

Renger JJ, Egles C, Liu G (2001) A developmental switch in neurotransmitter flux enhances synaptic efficacy by affecting AMPA receptor activation. Neuron 29:469-484.

Roos J, Kelly RB (2000) Preassembly and transport of nerve terminals: a new concept of axonal transport. Nat Neurosci 3:415-417.

Sala C, Piech V, Wilson NR, Passafaro M, Liu G, Sheng M (2001) Regulation of dendritic spine morphology and synaptic function by Shank and Homer. Neuron 31:115-130.

Sans N, Racca C, Petralia RS, Wang YX, McCallum J, Wenthold RJ (2001) Synapse-associated protein 97 selectively associates with a subset of AMPA receptors early in their biosynthetic pathway. J Neurosci 21:7506-7516.

Sans N, Prybylowski K, Petralia RS, Chang K, Wang YX, Racca C, Vicini S, Wenthold RJ (2003) NMDA receptor trafficking through an interaction between PDZ proteins and the exocyst complex. Nat Cell Biol 5:520-530.

Scannevin RH, Huganir RL (2000) Postsynaptic organization and regulation of excitatory synapses. Nat Rev Neurosci 1:133-141.

Scheiffele P (2003) Cell-cell signaling during synapse formation in the CNS. Annu Rev Neurosci 26:485-508.

Schnell E, Sizemore M, Karimzadegan S, Chen L, Bredt DS, Nicoll RA (2002) Direct interactions between PSD-95 and stargazin control synaptic AMPA receptor number. Proc Natl Acad Sci USA 99:13902-13907.

Serge A, Fourgeaud L, Hemar A, Choquet D (2002) Receptor activation and Homer differentially control the lateral mobility of metabotropic glutamate receptor 5 in the neuronal membrane. J Neurosci 22:3910-3920.

Setou M, Nakagawa T, Seog DH, Hirokawa N (2000) Kinesin superfamily motor protein KIF17 and mLin-10 in NMDA receptor-containing vesicle transport. Science 288:1796-1802.

Shapira M, Zhai RG, Dresbach T, Bresler T, Torres VI, Gundelfinger ED, Ziv NE, Garner CC (2003) Unitary assembly of presynaptic active zones from Piccolo-Bassoon transport vesicles. Neuron 38:237-252.

Sheng M, Kim E (2000) The Shank family of scaffold proteins. J Cell Sci 113:1851-1856.

Sheng M, Cummings J, Roldan LA, Jan YN, Jan LY (1994) Changing sub- 
unit composition of heteromeric NMDA receptors during development of rat cortex. Nature 368:144-147.

Steigerwald F, Schulz TW, Schenker LT, Kennedy MB, Seeburg PH, Kohr G (2000) C-terminal truncation of NR2A subunits impairs synaptic but not extrasynaptic localization of NMDA receptors. J Neurosci 20:4573-4581.

Sytnyk V, Leshchyns'ka I, Delling M, Dityateva G, Dityatev A, Schachner M (2002) Neural cell adhesion molecule promotes accumulation of TGN organelles at sites of neuron-to-neuron contacts. J Cell Biol 159:649-661.

Thomas U, Ebitsch S, Gorczyca M, Koh YH, Hough CD, Woods D, Gundelfinger ED, Budnik V (2000) Synaptic targeting and localization of discs-large is a stepwise process controlled by different domains of the protein. Curr Biol 10:1108-1117.

tom Dieck S, Sanmarti-Vila L, Langnaese K, Richter K, Kindler S, Soyke A, Wex H, Smalla KH, Kampf U, Franzer JT, Stumm M, Garner CC, Gundelfinger ED (1998) Bassoon, a novel zinc-finger CAG/glutaminerepeat protein selectively localized at the active zone of presynaptic nerve terminals. J Cell Biol 142:499-509.

Tovar KR, Westbrook GL (2002) Mobile NMDA receptors at hippocampal synapses. Neuron 34:255-264.

Tu JC, Xiao B, Naisbitt S, Yuan JP, Petralia RS, Brakeman P, Doan A, Aakalu
VK, Lanahan AA, Sheng M, Worley PF (1999) Coupling of mGluR/ Homer and PSD-95 complexes by the Shank family of postsynaptic density proteins. Neuron 23:583-592.

Valtschanoff JG, Weinberg RJ (2001) Laminar organization of the NMDA receptor complex within the postsynaptic density. J Neurosci 21:1211-1217.

Vardinon-Friedman H, Bresler T, Garner CC, Ziv NE (2000) Assembly of new individual excitatory synapses: time course and temporal order of synaptic molecule recruitment. Neuron 27:57-69.

Washbourne P, Bennett JE, McAllister AK (2002) Rapid recruitment of NMDA receptor transport packets to nascent synapses. Nat Neurosci 5:751-759.

Wenthold RJ, Prybylowski K, Standley S, Sans N, Petralia RS (2003) Trafficking of NMDA receptors. Annu Rev Pharmacol Toxicol 43:335-358.

Zhai RG, Vardinon-Friedman H, Cases-Langhoff C, Becker B, Gundelfinger ED, Ziv NE, Garner CC (2001) Assembling the presynaptic active zone: a characterization of an active zone precursor vesicle. Neuron 29:131-143.

Ziv NE, Garner CC (2001) Principles of glutamatergic synapse formation: seeing the forest for the trees. Curr Opin Neurobiol 11:536-543. 